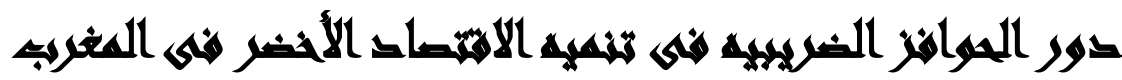

\section{تواسه تطليليه}

$[r r]$

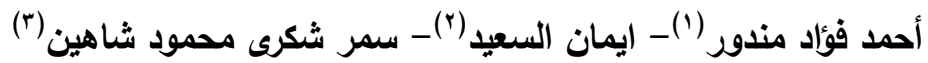

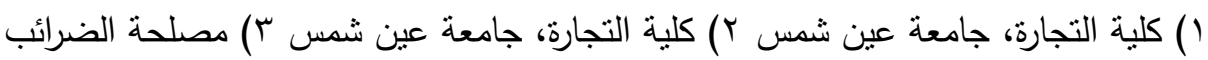

المصريه

\section{المستخلس}

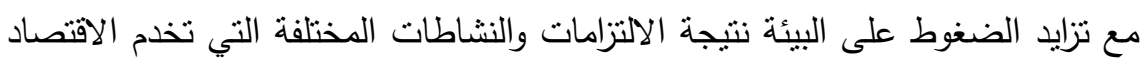

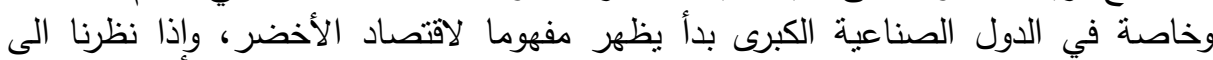

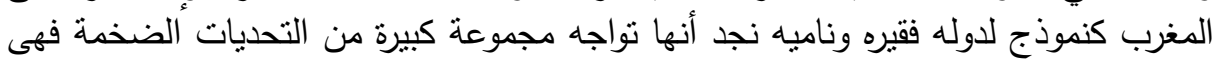

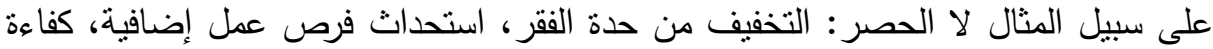
استخدام الموارد وأمن الطاقة، وضع استيراتيجيات منخفضة الكربون للتنمية الصناعية.

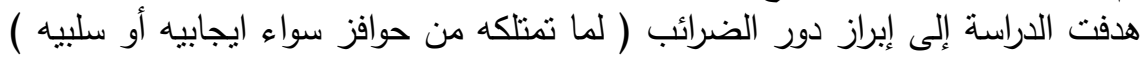

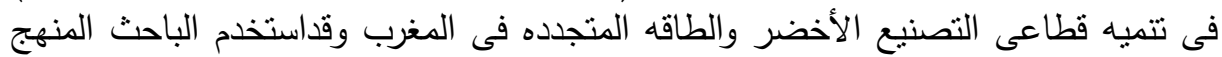

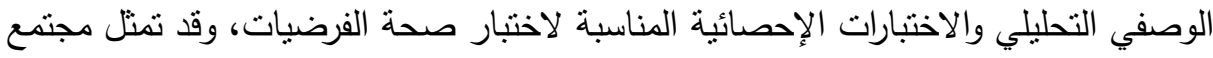

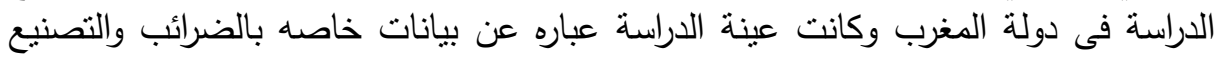

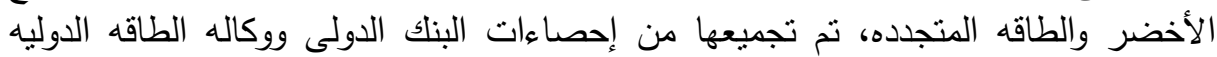

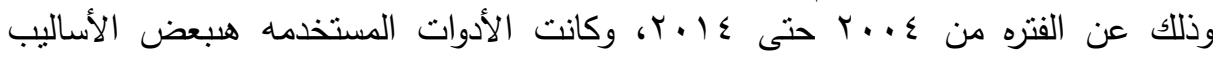
الإحصائيه مثل: معامل الارتباط البسيط لبيرسون، وتحليل الانحدار المتعدد بطريقة الانحدار التدريجى stepwise regression وقد أوضحت النتائج الآتى: ا. الضرائب على السلع والخدمات بالوحده النقديه المحليه والضرائب على السلع والتهات الخدمات

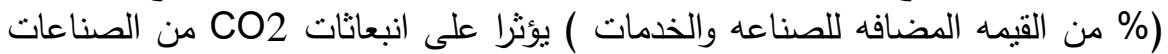

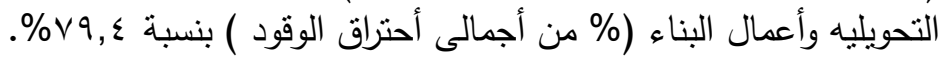

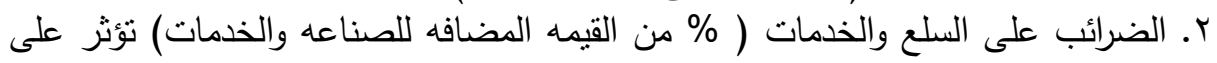

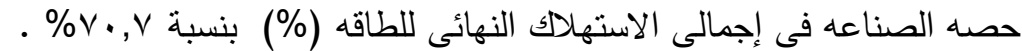

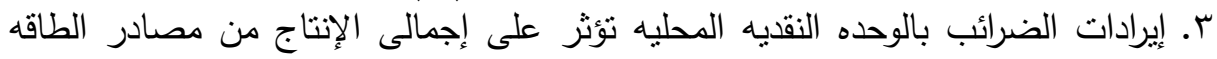

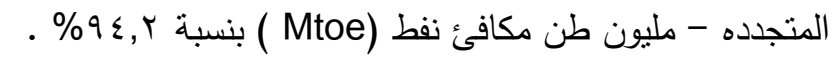

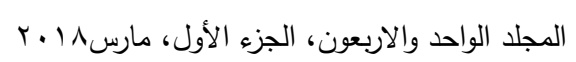


وفي ضوء ذللك خلصت الدراسة الى عدة توصيات أهمها: ادراج التكاليف البيئيه

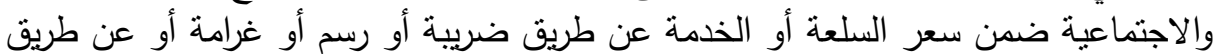
مخططات أرخص قابلة للتناول. الاقتصاد الأخضر بالمغرب - الطاقه المتجدده بالمغرب - الحوافز الضريبيه بالمغرب.

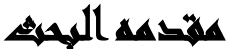

نظر التزايد المخاطر البيئية لم تعد المفاهيم الاقتصادية 》القديمةه التي أهملت أهية البعد البيئي في التتمية الاقتصادية ملائمة للتحليل الاقتصادي؛ إذ نمّ صياغة مفاهيم اقتصادية

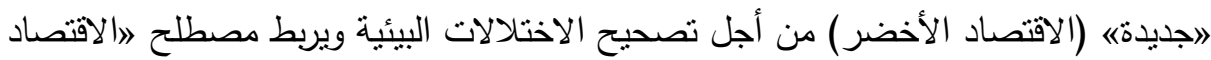

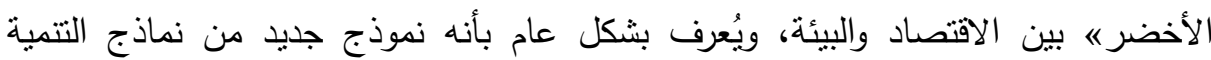

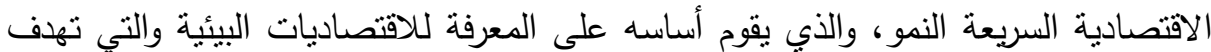
إلى معالجة العلاقة المتبادلة ما بين الاقتصاديات الإنسانية والنظام البيئي الطبيعي، والأثر

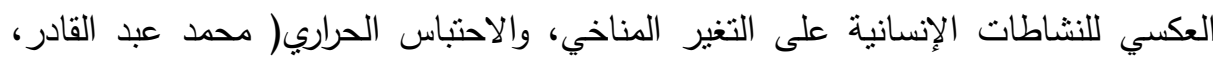
ـ ا · ) )، وهو يناقض نموذج ما يعرف بالاقتصاد البنى والذي أساسه يقوم على استخدام

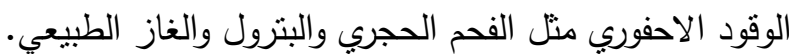

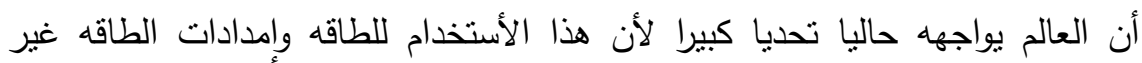
مستدام بيئيا، وفقا لوكاله الطاقه الدوليه [IEA]، مجموع الأستهلالك الصافى للكهرباء في العالم فضلا عن نوليد الكهرباء فى نزايد مستمر، كان نوليد الكهرباء فى العالم IVNA اليار كيلو

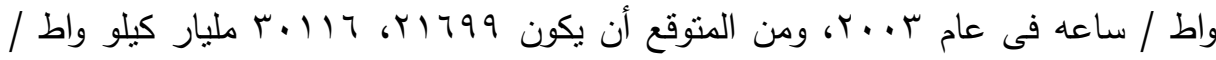

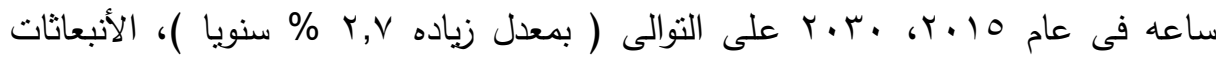

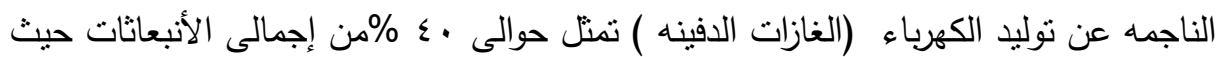

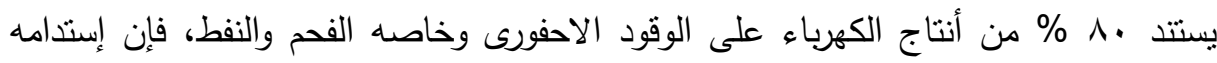
قطاع الطاقه لديها بالتأكيد تأثنير كبير على القدره التتافسيه للاقتصاد ودخل المواطن والتتميه

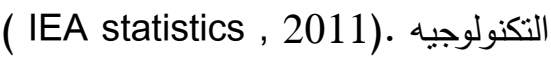


ومن هنا كان ضروريا التوجه الى الاقتصاد الاخضر، فهو اقتصاد يوجه فيه النمو فى الدخل والعماله بواسطة استثمارات فى القطاعين العام والخاص من شأنها ان تؤدى الى تعزيز

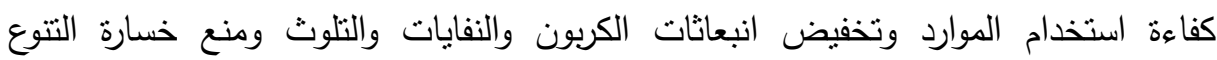

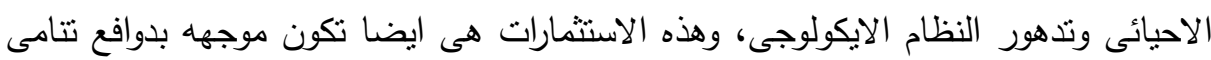

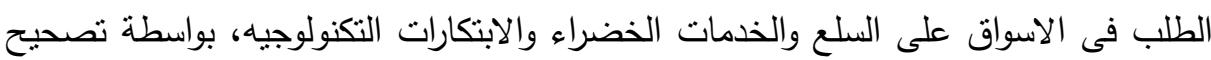
السياسات العامة الضريبية فيما يخص ان تكون الاسعار انعكاسا ملائما للتكاليف البيئية.

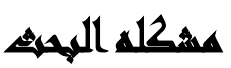

تتسم سياسات معظم الدول النامية ومنها المغرب بالثبات وعدم الحدائة وتماسكها بالنماذج الكلاسيكيه للإدارة وترتب على ذللك إعاقة الأنتقال الى الأقتصاد الأخضر ، وعابل وعند

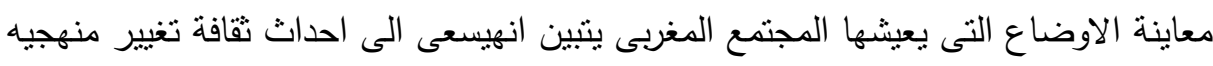
ذات رؤية استشراقية للمستقبل شاملة لنواحى الحياه كافه ولكن لايزال التخطيط باتشكاله

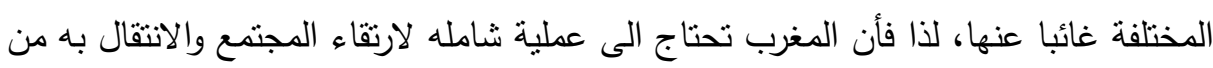
الوضع الثابت إلى وضع أعلى وأفضل، وما تصل إليه من حسن استغلال الطاقات والموارد التى تتوفر لديها والكامنه والموجوده وتوظيفها للأفضل، مع مراعاة حقوق الأجيال القادمه.

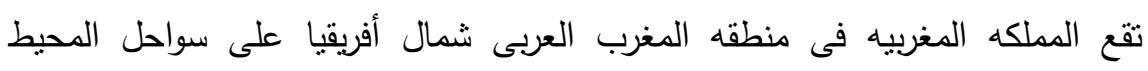

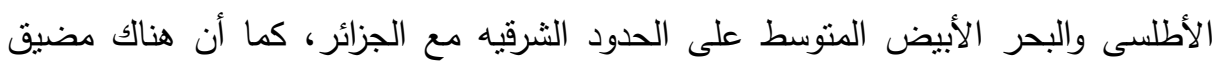

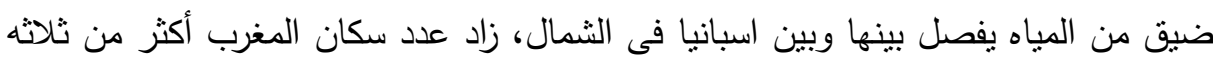

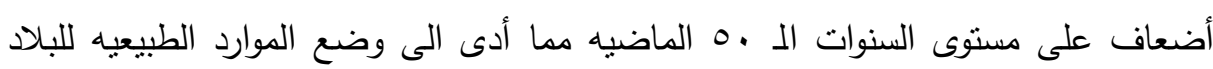
تحت ضغط. فى الوقت الحاضر تستورد المغرب نحو 9 \% \% من أمداداتها من موارد الطاقه، ارتفع

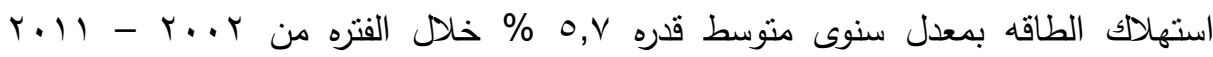

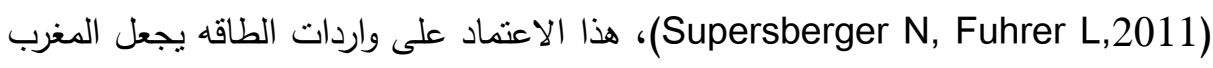

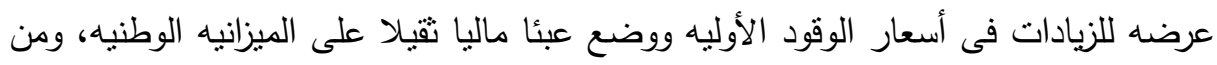

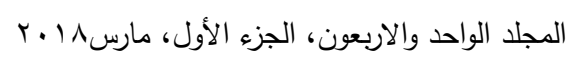


المثير للأهتمام أن نلاحظ أن ( وزاره الطاقه والمعادن والماء والبيئه ) تقدر سيناريوهين لمعدل

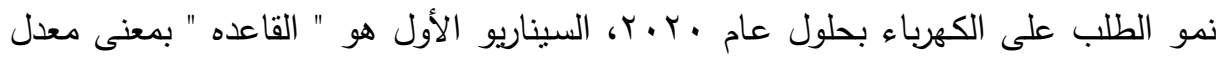

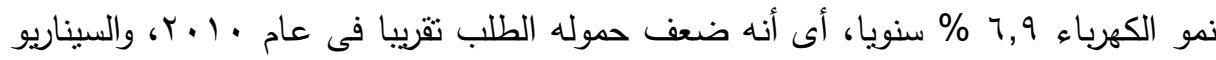

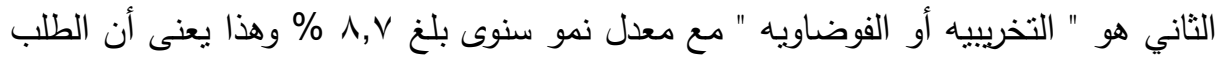

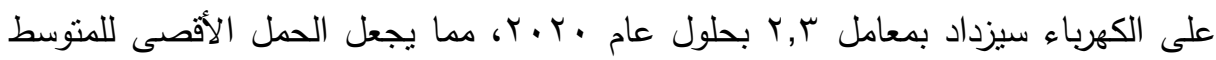

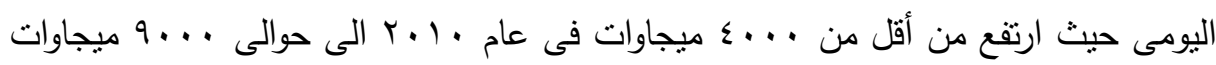

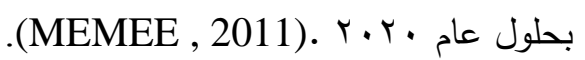
وبالتالى فإن المغرب يواجها فى المستقبل تكاليف ضخمه للطاقه إذا استمرت الأسعار فى الزياده، تحديات الطاقه الرئيسيه بالنسبه للمغرب هى كيف بمكن تحقيق إمدادات آمنه

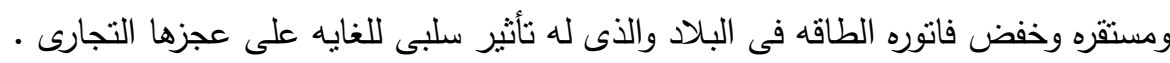

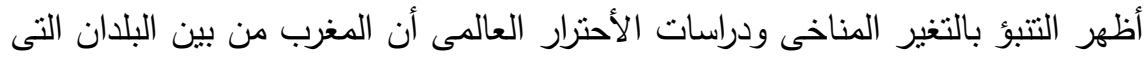

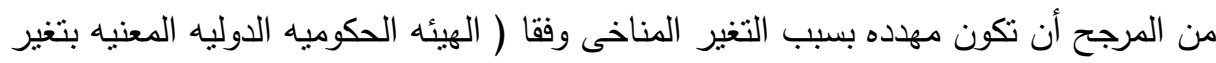

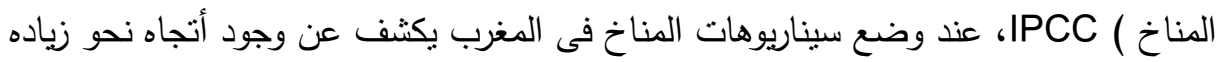

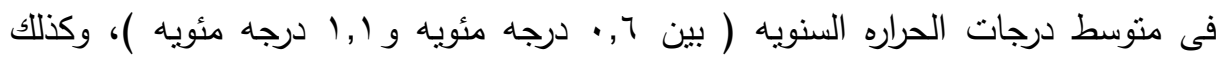

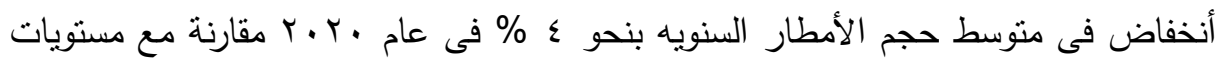

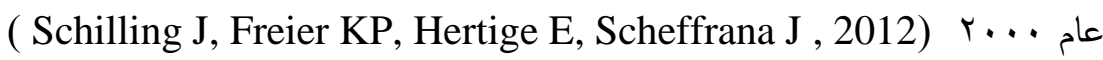
ووفقاً لوكاله الطاقه الدوليه، قدرت انبعاثات الغازات الدفينه فى المغرب من احتراق

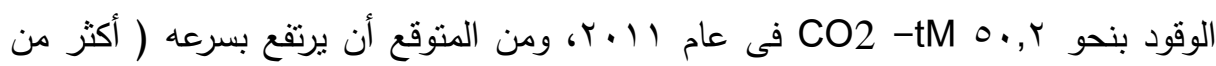

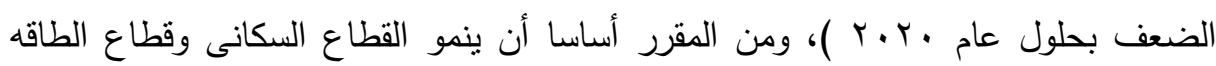

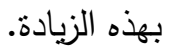

مما ذكر أعلاه يتضح أن آليه التتميه النظيفه هو نهج أساسي لاعم جهود الانتقال نحو

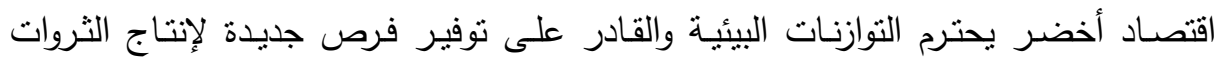

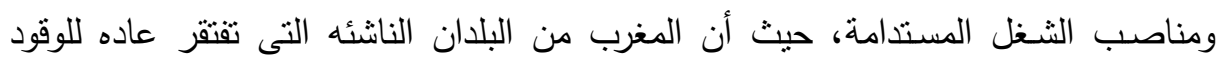


الأحفورى، ولكن تمنلك امكانيات كبيره للطاقه المتجدده، وخاصه موارد الطاقه الثمسيه وطاقه الرياح.

غير أن الأمر يتطلب اتخاذ تدابير مناسبة على صعيد السياسات الماليه لاتاحة الانتقال

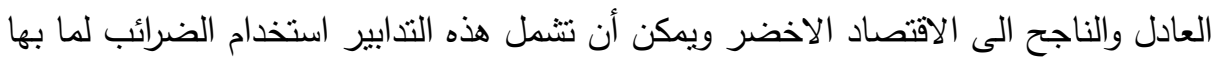
من حوافز ضريبيه تشجع الاستثمار والابتكار فى الأنشطة الخضراء ومعالجه تتشوهات كبيره

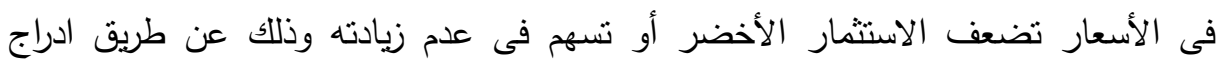
التكاليف البيئيه والاجتماعية ضمن سعر السلعة أو الخدمة عن طريق ضريبة أو رسم أو الو غرامة.

\section{أسريلا اللهيهم}

وأمام هذه المعطيات فإن التساؤل المطروح الذى يشكل محور الدراسه هو: ما الأجراءات أو

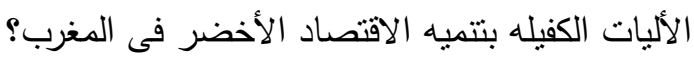
1- ما الدور الذى تقوم به الحوافز الضريبيه فى تخفيض انبعانات ثنانى أكسبد الكربون؟ r- ما الدور الذى تقوم به الحوافز الضريبيه فى نرشيد الاستهلاك النهائي للطاقه؟

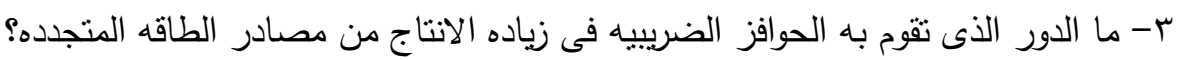

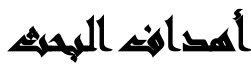

• تحليل دور الحوافز الضريبيه فى تتميه التصنيع الأخضر بالدغرب. • دراسه دور الحوافز الضريبيه فى تتميه قطاع الطاقه المتجدده بالمغرب.

\section{هروضر الهمهي}

لما كان هدف البحث دراسه دور الحوافز الضريبيه فى تتميه الاقتصاد الاخضر فى هي المغرب فأن البحث يقوم على اختبار مدى صحه الفروض النالية: 
الفرض الاول: لا توجد علاقه معنوية بين الحوافز الضريبية وتتمية التصنيع الأخضر

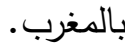

الفرض الثاني: لاتوجد علاقه معنوية بين الحوافز الضربيية وتتمية الطاقه المتجددة بالمغرب.

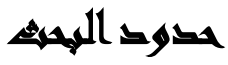

الحدود الزمنيه: سنركز فى بحثنا على الفتره الزمنيه من سنه ع ... حتى ع ( ب حيث حيث أزدهر خلال هذه الفتره مفاهيم منل الأقتصاد الأخضر والتتميه المستدامه والتغير المناخى وأحتلت هذه المفاهيم مساحات واسعه من أجنده قاده العالم، كما ان هذه الفتره ستكون كافيه لإجراء الدراسه التحليليه المطلوبه للوقوف على طبيعه المتغيرات واستخلاص دلالتها. الحدود المكانية: نم اختيار المملكه المغربيه كنموذج لدوله ناميه تسعى نحو اقتصاد أخضر منخفض الكربون تمتلك استيراتيجيه وطنيه للطاقه مع التركيز على تتمية الطاقات المتجدده، وتعزيز كفاءة الطاقه، ويرجع ذلك أساسا الى توافر الموارد المتجدده.

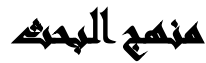

تعتمد هذه الدراسة على استخدام المنهج الوصفى التحليلي العلمى الذي يساعد على

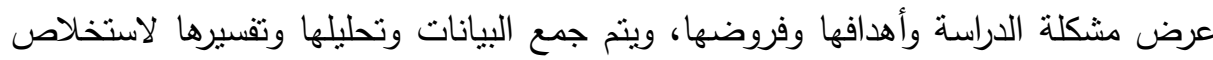
دلالاتها ونصل عن طريق ذلك إلى إصدار التوصيات.

\section{أهمبه المهمث}

تكمن أهميه هذا البحث في تسليط الضوء على أداه من أهم أدوات السياسه الماليه للدوله

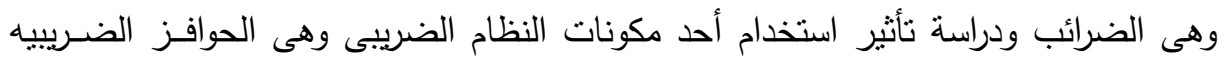
لكساعده الدوله الناميه ( المغرب) لخضرنه اقتصادها. 


\section{المسطلحائ والمهاهميه}

الحوافز الضريبيه: ميزة اقتصادية قابلة للتقدير تقدم لفعالية انتاجية معينة او لانواع من الفعاليات وبتوجيه من الحكومات لتتجيعها للتصرف بالثكل المرغوب وتهدف الى زيادة معدل

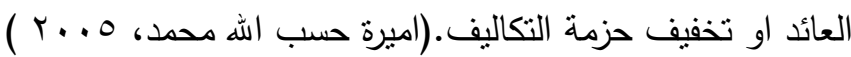
الاقتصاد الأخضر : عرفبرنامج الأمم المتحده للبيئه (UNEP) الأقتصاد الأخضر بأنه: " الأقتصاد الذى يؤدى إلى تحسين رفاه الإنسان والحد من عدم المساواه على المدى البعيد، من دون تعريض الأجيال المستقبليه لمخاطر تدهور النظم البيئيه و ولندرة الموارد الإيكولوجيه

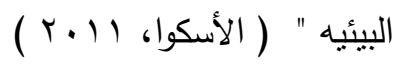

الطاقه المتجدده: فهى الطاقات التى نحصل عليها من خلال نيارات الطاقه التى يتكرر وجودها فى الطبيعه على نحو تلقائي ودوري، وهى بذللك على عكس الطاقات غير المتجدده الموجوده غالبا فى مخزون جامد فى الارض لا يمكن الافاده منها ألا بعد تدخل الانسان لأخراجها منه (Ciolkosz Daniel)

\section{التوراسايت المابرهي}

ا. دراسة هدى فوزي عبد العال ع 1 ـ ب : حيث أبرزت الباحثه أهميه الدور الذي يمكن أن يلعبه النظام الضريبي بمختلف آدواته فى التأثير الإيجابى على قرارات الوحدات الأقتصاديه من أجل تخفيض مستويات التلوث الى حدود مقبوله، وتوصلت الى أن الحافز الضريبي ما هو إلا آداه فاعليتها تتوقف على من يستعمل هذه الآداه، وأن سياسه الحوافز الضريبيه لا تتعارض مع مبدأ العداله، إذ أنها تمنح بهدف تصني تحقيق العداله النهائيه بين

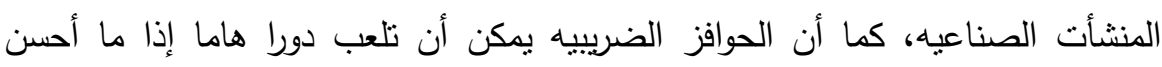

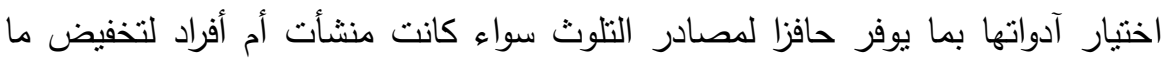
يصدر عنها من وحدات تلوث. 


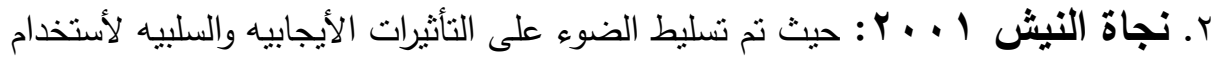
الطاقه على الجانبين التنموى والبيئي ومتطلبات كفاءه وترشيد الأستهلاك لخدمه التتميه المستديمه، وتوصلت الى ضرورة محابهه الآثار السلبيه للطاقه وأحلال الطاقات المتجدئ التهاه بصوره خاصه فى الوطن العربي لعزيز أستدامه موارده الناضبه .

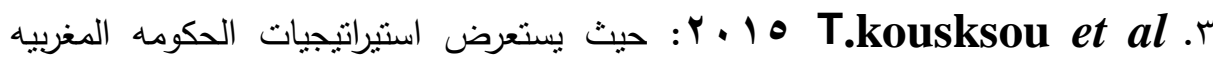
لتحقيق التتميه المستدامه والقائمه على تشجيع استخدام الطاقات المتجدده وكفاءه الطاقه، وتم التوصل الى أن المغرب تمنلك استيراتيجيه وطنيه للطاقه مما يضع المغرب من بين البلدان الأكثر طموحا فى جميع أنحاء العالم فى تعزيز التتميه المستدامه، ونتيجه لذلك فقد كان للمغرب نقطة محوريه فى استثمارات كبيره فى مجال الطاقه المتجدده ويرجع ذلك أساسا الى توافر الموارد المتجدده. ع. Erin Elizabeth Troland 10 م ب : حيث تم تسليط الضوء على الأنفاق العام والضرائب فى الدول الناميه والدور الذى يمكن أن يلعبه النظام الضريبي بمختلف آدواته

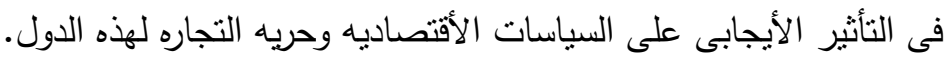
لأجل الوصول الى أهدف البحث فقد قسم الى ثلاث أجزاء هي:

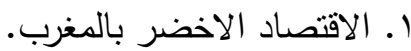
r. الاستراتيجية الطاقية والطاقه المتجدده بالمغرب.

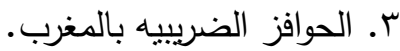

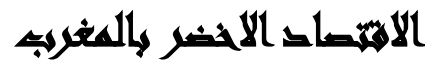

الاقتصاد الأخضر يعد أحد الرهانات الرئيسية التي انخرط فيها المغرب، أكدت وثيقة

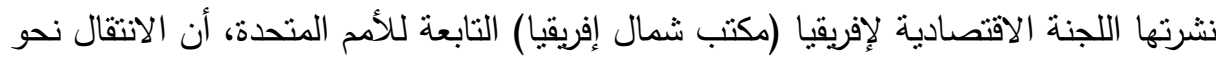

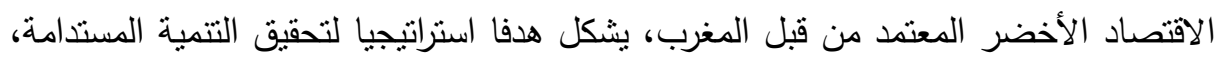
وجاء في هذه الوثيقة، التي حملت عنوان "الاقتصاد الأخضر في المغرب"، أن الإكراهات

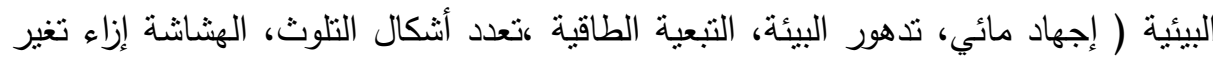


المناخ )، فرضت إعادة توجيه النموذج الاقتصادي نحو اقتصاد أخضر ومدمج يستتد إلى القطاع الخاص وقادر على توفير فرص الثغل وتقليص الفقر وتسوية اختلالات التتمية

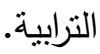

وفي معرض تطرق الوثيقة للجانب المتعلق بالاستثمارات الخضراء، أوضحت أن المغرب يسير في هذا التوجه، حيث جرى إقرار الميثاق الوطني للبيئة والتتمية المستدامة سنة ب ا ـr،

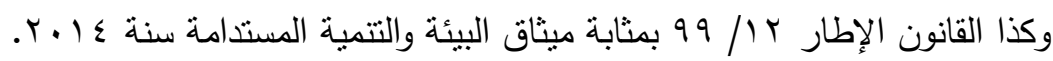
وبالإضافة إلى ذلك، جرى اعتماد خارطة الطريق للنمو الأخضر والتتمية الترابية، وذلك في إطار أنشطة مجموعة التركيز التي يقودها المغرب، والتي سميت ب "مبادرة منطقة الثرق إنى

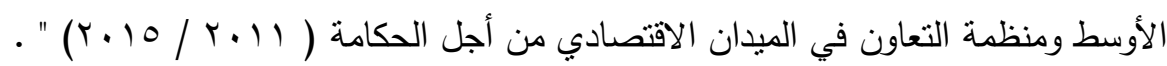

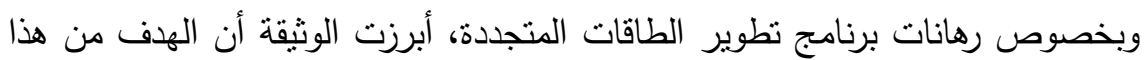

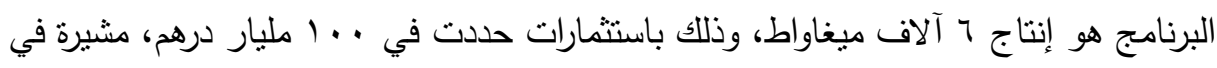
الوقت ذاته إلى أن إنجاز هذا البرنامج سيمكن من تفادي انبعاث مر ب مليون طن من ثاني أوكسيد الكربون سنويا. وتقدر إمكانات خلق فرص العمل التي يمكن لمساللك الطاقات المتجددة في المغرب

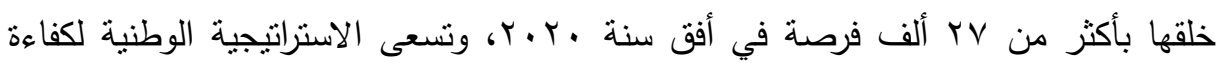

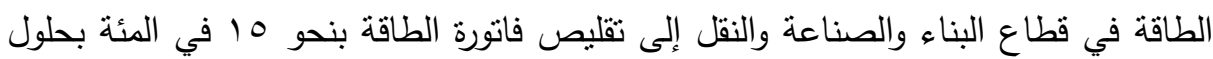

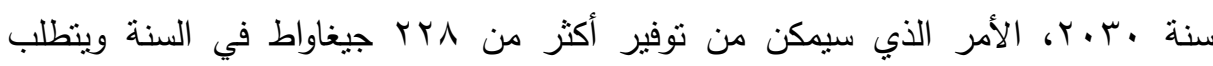

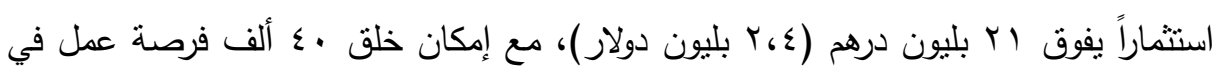

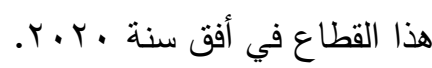
أما المخطط الوطني للتطهير السائل وتصفية المياه العادمة، الذي تبلغ ميزانيته بـأبـ

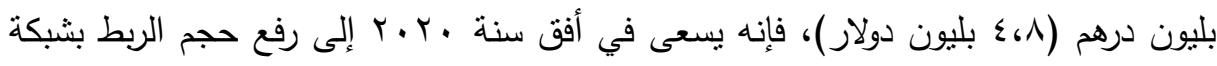

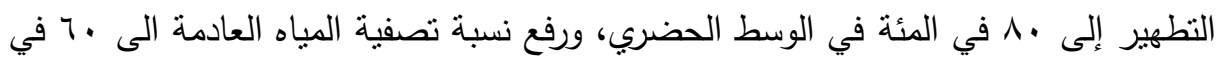

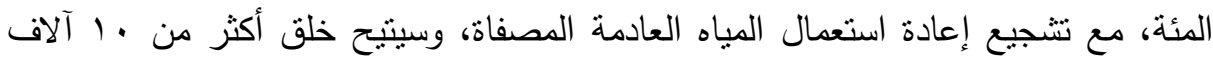

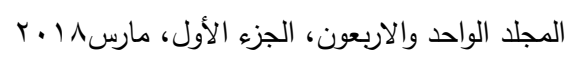


فرصة عمل مباشر، زيادة على الفرص المتوقعة في المسلك الصناعي المتعلق بإنتاج

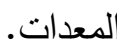
ويستهدف البرنامج الوطني للنفايات المنزلية تحسين تجميع هذه النفايات والحد المناسب

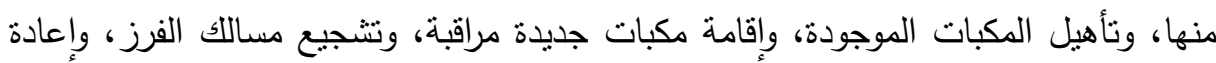

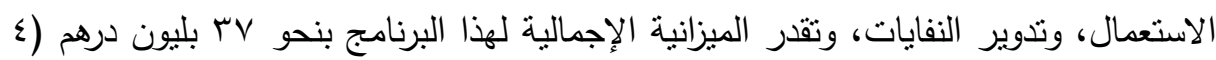

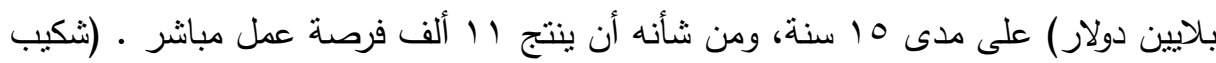

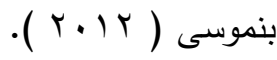
وفيما يلي بعض المؤثرات الرئيسية الدولية تلد على التقام المحرز :

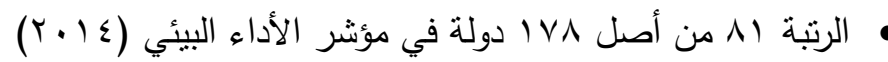

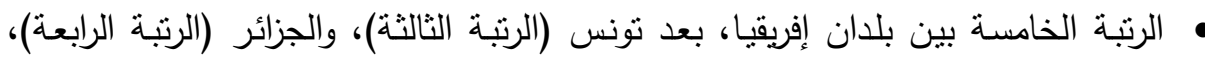

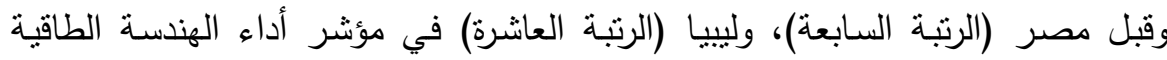

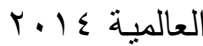

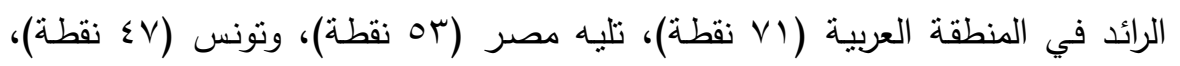

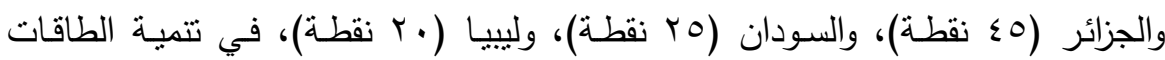

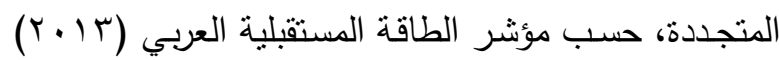
رائد في مكافحة الأحتباس الحراري في أفريقبا وفي العالم العربي، إذ يحتل الرتبة

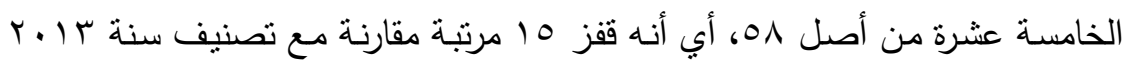

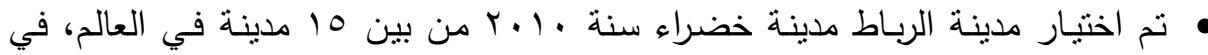

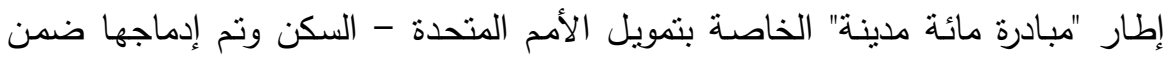

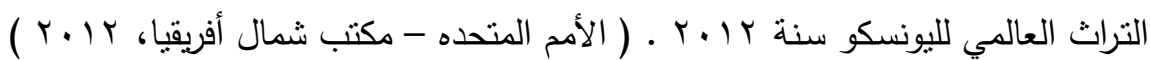
وهنـاك مبادرات مهمة في طور الإنجـاز مـن أجلـ

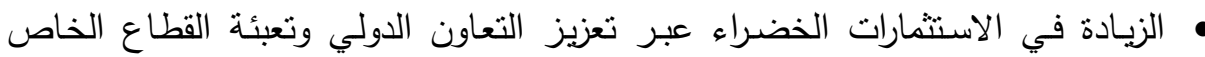

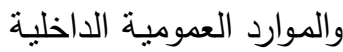
تشجيع سياسة صناعية قادرة على توفير فرص الشغله 
تعزيز الكفاءات والابتكار في مجال التكنولوجيا الخضراء.

ومن المتوقع أن تغذي الدروس المستخلصة من المبادرات والبراهـج القطاعيـة الجاري

تتفيذها التفكير وانتقاء الخيارات في إطار الأعداد لأستراتيجية ضرورية شاملة تهيكل

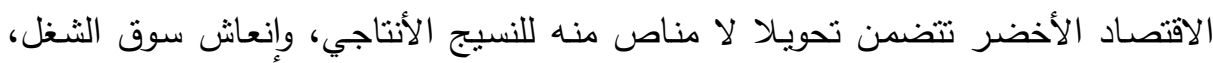
والأبتكار والبعد الترابي.

\section{الاستراتيجية الطاقية والطاقه المتجدده بالمغرب:}

تهدف الأستراتيجية الطاقية الوطنية التي تم تبني مضامينها خلال المناظرة الأولى للطاقه

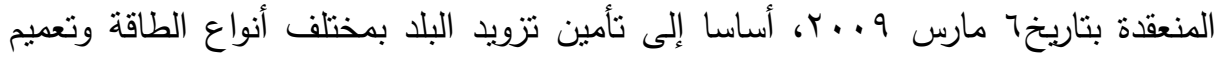

الوصول إليها بأثمنة مناسبة، وترشيد استعمالها معا لأخذ بعين الأعنبار الحفاظ على البيئة.

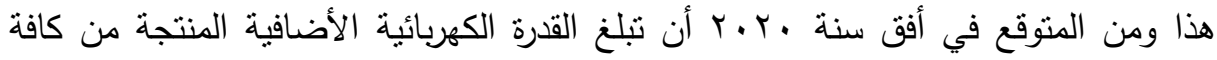

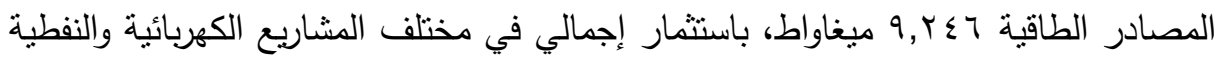

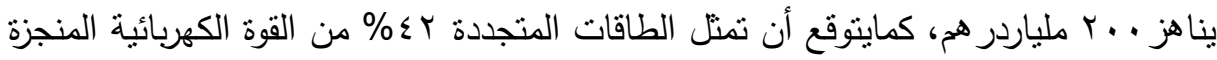

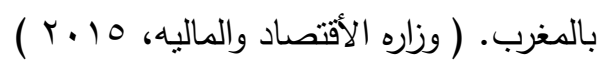

ومنذ إعطاء انطلاقة للأستراتيجية الطاقية الوطنية كانت المنجزات الرئيسية كما يلي: 1. تقوية العرض الكهربائي من خلال إنشاء . .ــ, إعياواط كقدرة طاقية إضافية باستثمار إجمالي يصل إلى ع ا ملياردر هم. r. ت تتمية الطاقات الخضراء من خلال تفعيل البرامج التالية:

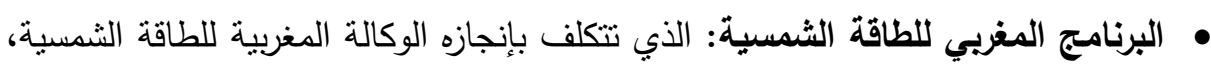

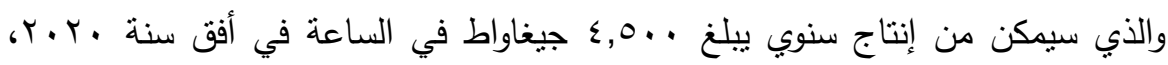

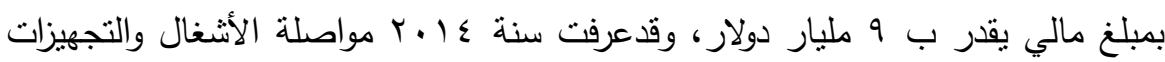

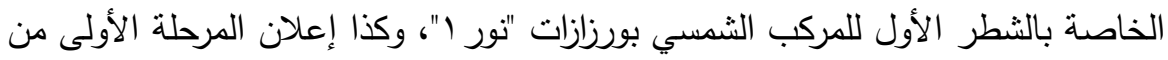

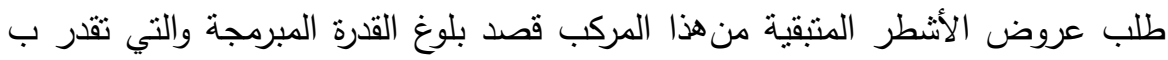

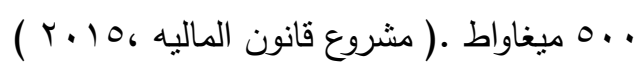




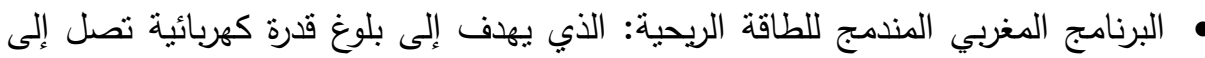

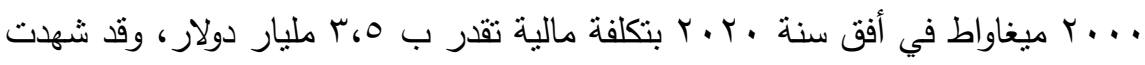

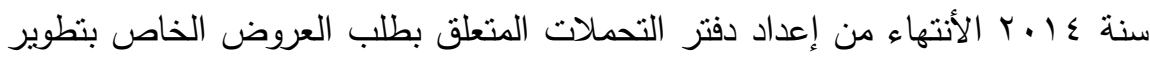

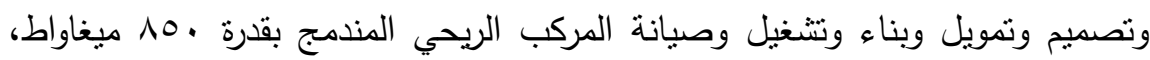

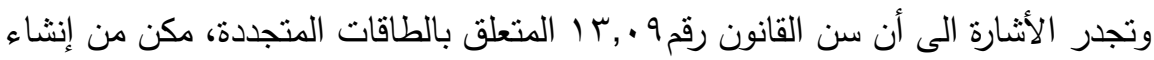

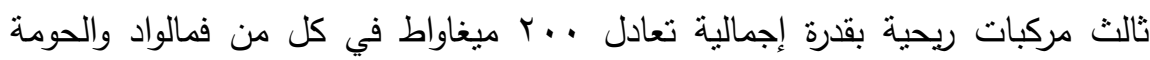
وأخفنير وذلك من طرف شركات خاصة .(مشروع قانون الماليه، 0 ـ ب ) ).

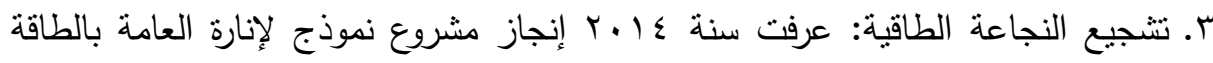
الثنمسية بفاسو كذا مشاريع توضيح تقنيات النجاعة الطاقية في مجال البناء، كما تم توقيع

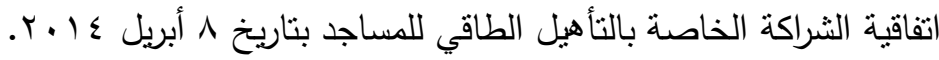

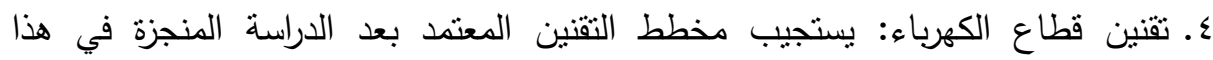

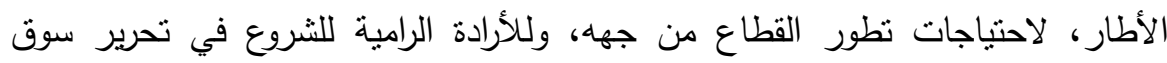

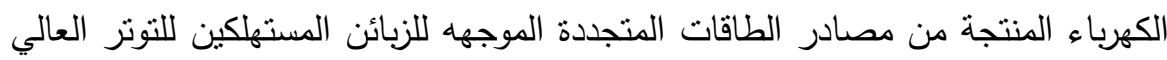
جداوالتوتز العالي من جهه أخرى، كما يعتزم هذا المخطط الفصل بين أنشطة الفاعل

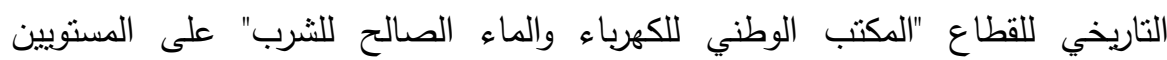
التنظيمي والمحاسبي وإحداث مدبر لنبكة نقل الكهرباء. وستتميز سنة 1 ـ ـ ب أساسا بمواصلة العمليات والبرامج التالية:

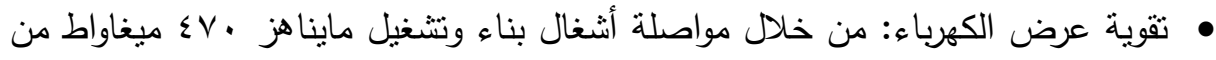

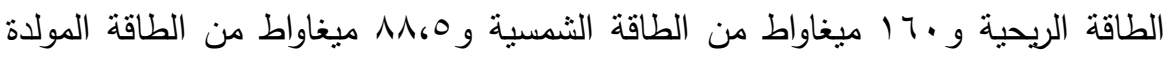
بالديزل وذللك بغلاف استثماري يصل إلى به، أ مليار دهم.

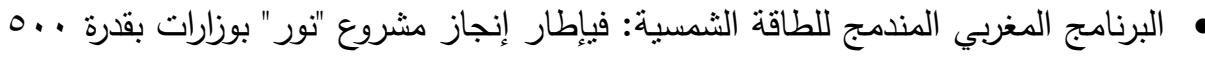

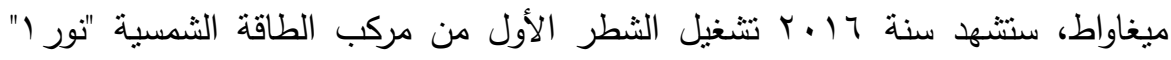

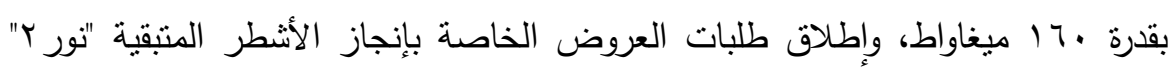

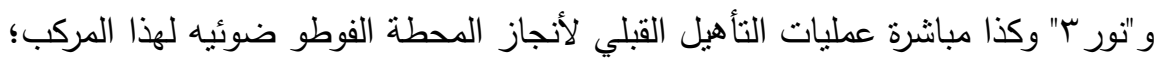


• البرنامج المغربي للطاقة الريحية: ستعرف سنة 1 • بتتغيل المحطة الريحية لإتتاج

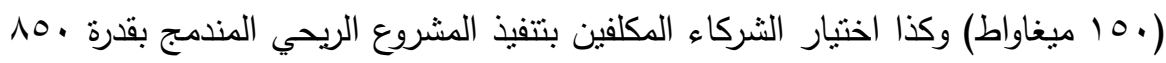
ميغاواط؛ المشاريع الريحية للقطاع الخاص: ستشهد سنة 1 • ب نشييد المحطة الريحية لجبل الخالدي بقدرة • T أميغاواط وكذا نتغيل المحطات الصغرى الكهرومائية بقدرة إجمالية تصل إلى •ـ ميغاواط المخطط الوطني للنجاعة الطاقية: ستتميز سنة 17 ـ ب خصوصا بتنبني الحالات العامة

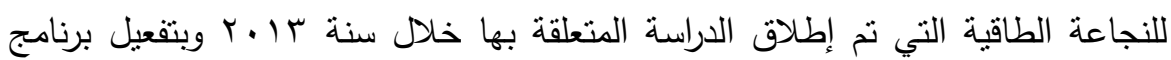
التأهيل الطاقي للمساجد وبتعميم التدقيق الطاقي وبإدماج النجاعة الطاقية على مسنوى القطاع الصناعي وكذا قطاع النقل وتفعيل إجراءات خاصة بزبائن التوتز العالي جدا

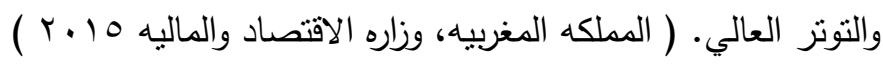
الحوافز الضريبيه بالمغرب:

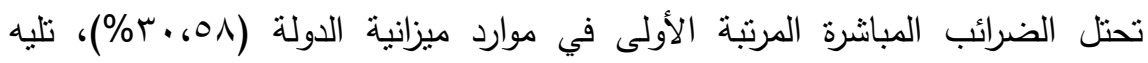

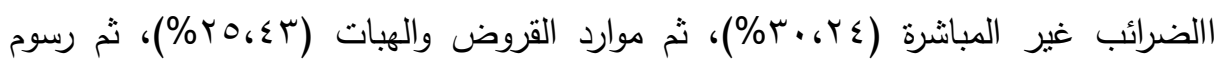

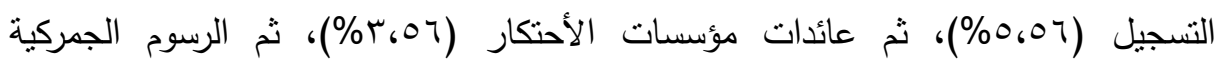

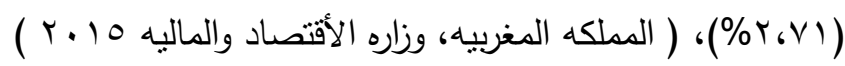

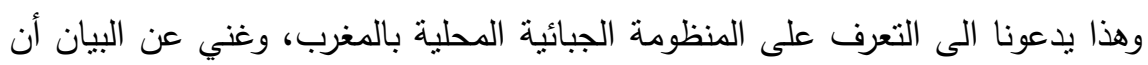

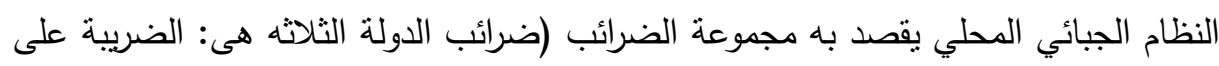
الشركات، الضريبة على الدخل، الضريبة على القيمة المضافة) والرسوم المستحقة لفائدة الجماعات المحلية وهيآتها، بطريقة مباشرة أوغير مبانشرة، أب تلك التي يرجع حق استخلاصها

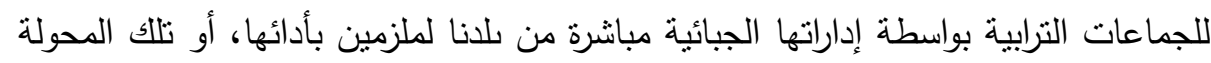

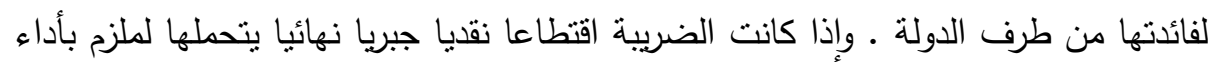
الضريبة وفقا لمقدرته التكليفية، مساهمة في الأعباء العامة، وذلك وفقا لنص الفصل وهب من هن

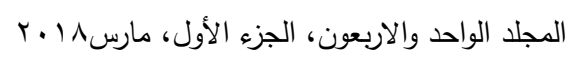




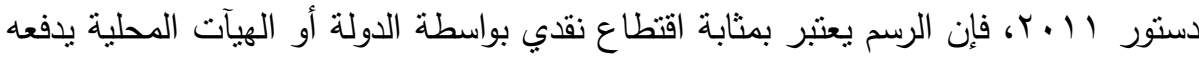
جبرا مقابل نفع خاص يحصل عليه.

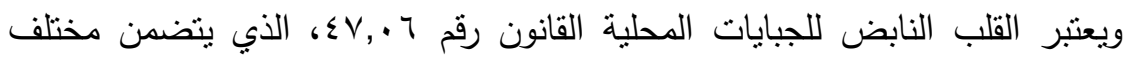
الرسوم المستحقة لفائدة الجماعات الحضرية والقروية، والبالغ عددها إحدى عشر رسما،

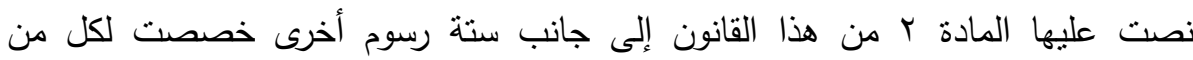

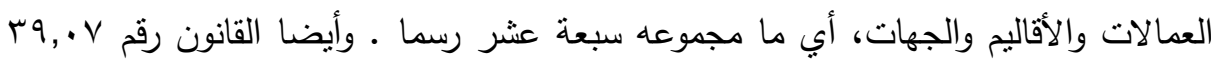
المتعلق ببعض الرسوم والحقوق والمساهمات والأتاوى المستحقة لفائدة الجماعات

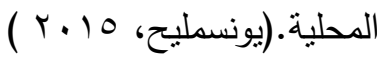

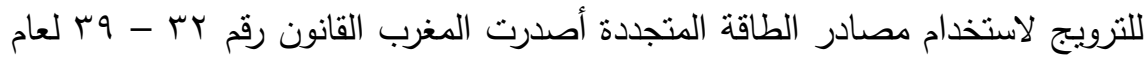
ـ99 199 والضرائب.

\section{إلجراءاهي الهبه}

ولما كان الانتقال نحو اقتصاد أخضر منخفض الكربون يمثل هدفا أسنتراتيجيا للمملكه المغربيه لذا نم اختيارها كمجتمع للاراسه، وكانت عينه الدراسه المستخدمه: عباره عن بيانات

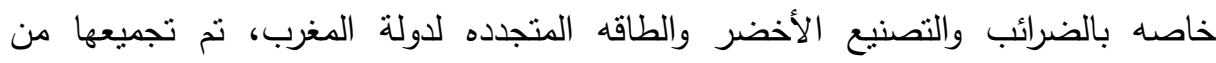

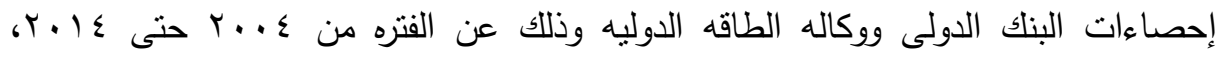
وكانت الأدوات المستخدمه فى هذه الدراسهرى بعض الأساليب الأحصائيه مثل: معامل

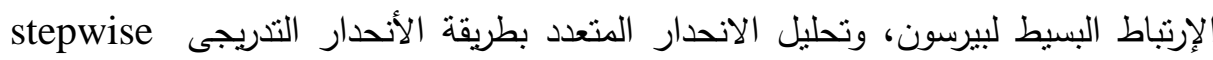
.regression

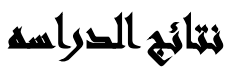

اختبار صحة فروض الدراسة: اختبار صحة الفرض الأول:لا توجد علاقه معنويه بين

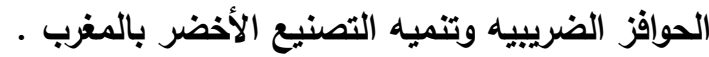




\section{كتغنيوالتص القراسما}

\begin{tabular}{|c|c|c|}
\hline 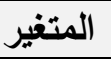 & 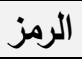 & \\
\hline التابع & Y1 & أحنراق الوقود) CO2 من الصناعات التحويليه وأعمال البناء( \% من أجمالى \\
\hline التابع & Y2 & القيمه المضافه للصناعات التحويليه ( \% من الناتج المحلى الأجمالى) \\
\hline التابع & Y3 & 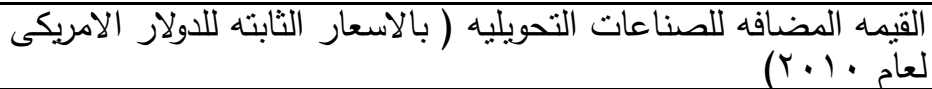 \\
\hline 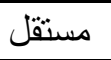 & $\mathrm{X} 1$ & إيرادات الضرائب \% من الناتج المحلى الأجمالى \\
\hline 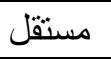 & $\times 2$ & إيرادات الضرائب بالوحده النقديه المحليه \\
\hline مستقل & $\times 3$ & والخدائب على السلع والخدمات(\% من القيمه المضافه للصناعه \\
\hline 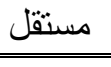 & X4 & الضرائب على السلع والخدمات بالوحده النقديه المحليه \\
\hline
\end{tabular}

جدول(1) يوضح معاملات الارتباط بين المتغيرات المستقلة والمتغير التابع

\begin{tabular}{|c|c|c|c|c|}
\hline $\mathbf{X 4}$ & $\mathbf{X 3}$ & $\mathbf{X 2}$ & X1 & \\
\hline$* *, \Lambda \leqslant \Gamma-$ & $*, \vee V \cdot q$ & $*,, 7) \leq-$ & $* *,, \vee \vee \wedge$ & Y1 \\
\hline$* * \cdot, \vee \Gamma \wedge-$ & $* *, \vee \vee 90$ & **., $\vee १ \leqslant-$ & $* *, \Lambda \backslash \Gamma$ & $\mathrm{Y} 2$ \\
\hline$* *, 901$ & $* *, \wedge T$ & ***, ^৭१ & $* \cdot, V \cdot q$ & $\overline{\mathrm{Y3}}$ \\
\hline
\end{tabular}

\section{يتضح من بيانات الجدول السابق:}

ا. وجود علاقة ارتباط طردية دالة احصائيا بين انبعاثات CO2 من الصناعات التحويليه

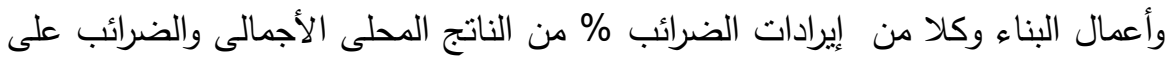

السلع والخدمات ( نسبة من القيمه المضافه للصناعه والخدمات )، حيث بلغت قيمة

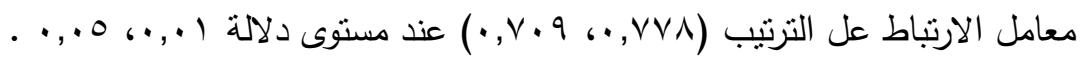

r. وجود علاقة ارتباط عكسية دالة احصائيا بين انبعاثات CO2 من الصناعات التحويليه

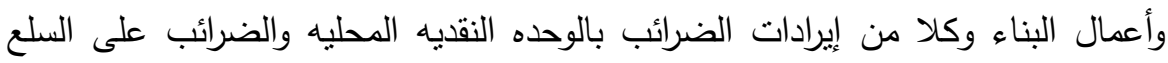

والخدمات بالوحده النقديه المحليه حيث بلغت قيمة معامل الارتباط عل الترتيب (- برديه

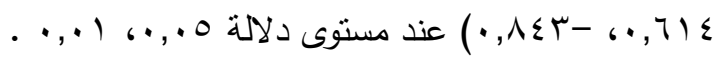

r. وجود علاقة ارتباط طردية دالة احصائيا بين القيمه المضافه للصناعات التحويليه (ب ( من من الناتج المحلى الأجمالى) وكلا من إيرادات الضرائب \% من النه الناتج المحلى الأجمالى

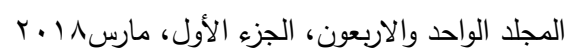


والضرائب على السلع والخدمات ( نسبة من القيمه المضافه للصناعه والخدمات )، حيث

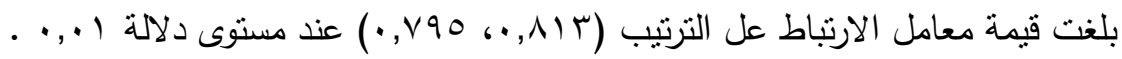

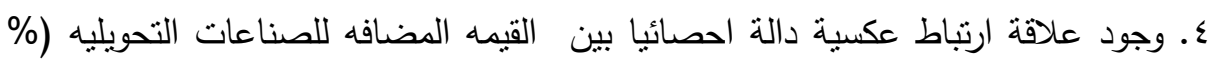
من الناتج المحلى الأجمالى) وكلا من إيرادات الضرائب بالوحده النقديه المحليه

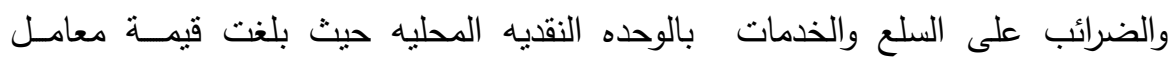

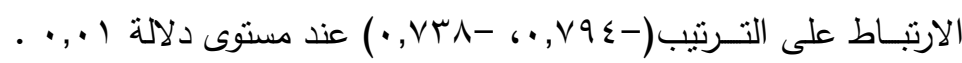

ه. وجود علاقة ارتباط طردية دالة احصائيا بين القيمه المضافه للصناعات التحويليه

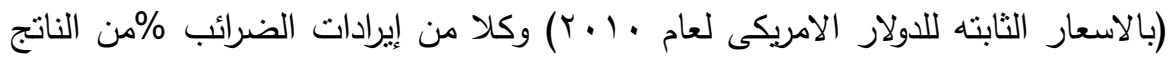

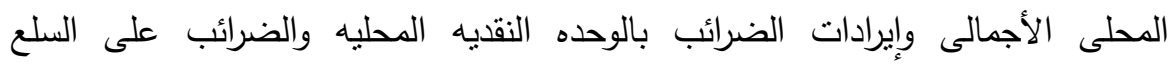
والخدمات (نسبة من القيمه المضافه للصناعه والخدمات) والضرائب على السلع والخدمات

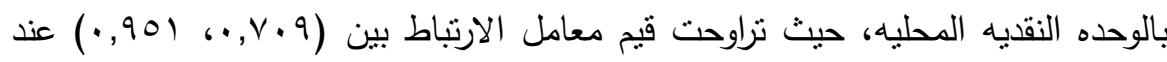

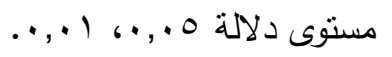

ومن خلال النتائج السابقة نم اجراء تحليل الانحدار المتعدد بطريقة الانحدار التدريجي لمعرفة اثر المتغيرات المستقلة وايهم اكثر تأثنر على المتغير التابع.

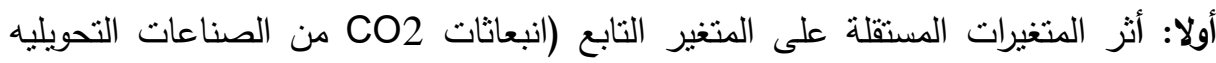
وأعمال البناء ( \% من أجمالى أحتراق الوقود ):

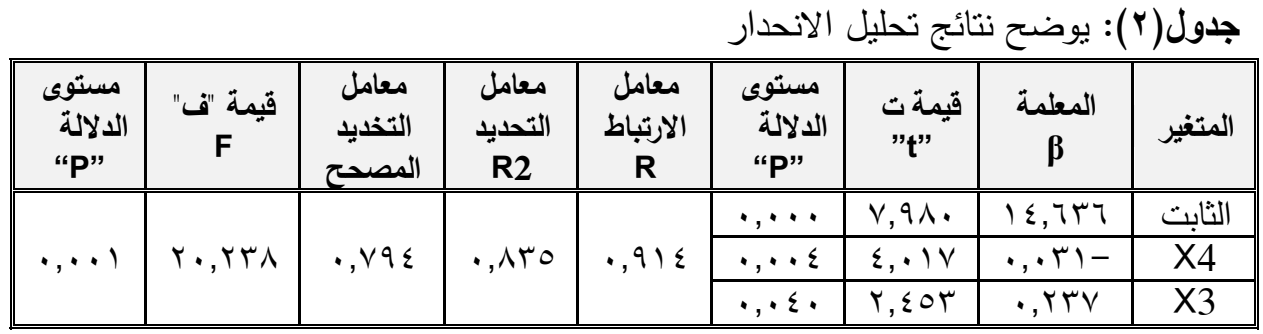

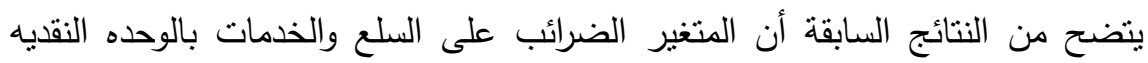
المحليه والمتغير الضرائب على السلع والخدمات ( \% من من القيمه المضافه للصناعه والخدمات) يؤثرا على أنبعاثات CO2 من الصناعات التحويليه وأعمال البناء (\% من أجمالى 
أحتراق الوقود ) بنسبة ؟,\% \% وان التغير في أنبعاثات CO2 من الصناعات التحويليه وأعمال البناء ( \% من أجمالى أحتراق الوقود ) بمقدار الوحدة بسببه التغير في الضرائب على لونى

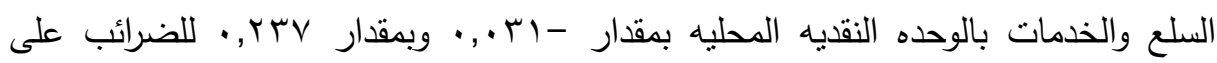
السلع والخدمات ( \% من القيمه المضافه للصناعه والخدمات ) $+0.237 \times 3 Y 1=14.636-0.031 \times 4$

ثانياً: اثر المتغيرات المستقلة على المتغيرالتابع (القيمه المضافه للصناعات التحويليه ( \% من

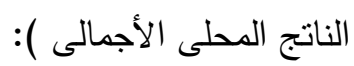

\begin{tabular}{|c|c|c|c|c|c|c|c|c|}
\hline $\begin{array}{l}\text { الدلالة مستوى } \\
\text { "P" }\end{array}$ & قيمة "ف" & التذديد & التحديد & $\begin{array}{c}\text { الارتباط } \\
\text { R }\end{array}$ & $\begin{array}{l}\text { مستولة "P" } \\
\text { "P" }\end{array}$ & قيمة "t" & المعلمة & المتغير \\
\hline \multirow[t]{2}{*}{$\cdot, \ldots$} & \multirow[t]{2}{*}{$I V, 0 \cdot Y$} & \multirow[t]{2}{*}{ זrד, } & \multirow{2}{*}{. } & \multirow{2}{*}{ • } & $\cdot, \ldots$ & $11, \wedge 01$ & $r V, 10 V$ & الثابت \\
\hline & & & & & 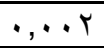 & $\varepsilon, 1 \wedge \varepsilon$ & $\cdot, \S \backslash \wedge$ & $\mathrm{X} 1$ \\
\hline
\end{tabular}

ومن النتائج السابقة يتضح ان إيرادات الضرائب \% من الناتج المحلى الأجمالى تؤئز

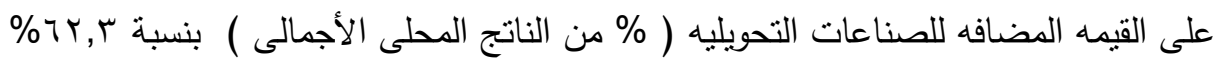
وان التغير في القيمه المضافه للصناعات التحويليه ( \% من الناتج المحلى الأجمالى ) بمقدار الوحدة يسببه التغير في إيرادات الضرائب \% من الناتج المحلى الأجمالى بمقدار $\cdot, \Sigma) \wedge$ $\mathrm{Y} 2=27.157+0.418 \times 1$

ثالثاً: اثر المتغيرات المستقلة على المتغيرالتابع القيمه المضافه للصناعات التحويليه (بالاسعار

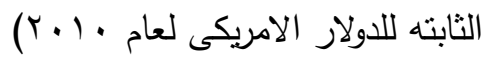

\begin{tabular}{|c|c|c|c|c|c|c|c|c|}
\hline & & & & & لانحدار & كـج تحأ & : يوضر & جدول \\
\hline $\begin{array}{c}\text { مستولةى } \\
\text { "P" }\end{array}$ & "قيمة & التخديد & $\begin{array}{l}\text { التحديد } \\
\text { معامل }\end{array}$ & $\begin{array}{c}\text { معامبط } \\
\text { R } \\
\text { Reباط }\end{array}$ & $\begin{array}{c}\text { الدلالة مستوى } \\
\text { "P” }\end{array}$ & قيمة ت" & المعلمة & المتغير \\
\hline \multirow{2}{*}{$\cdot, \cdots$} & \multirow{2}{*}{$10,9 \varepsilon$} & \multirow{2}{*}{$\cdot, 190$} & \multirow{2}{*}{$\cdot, 9.0$} & \multirow{2}{*}{$\cdot, 901$} & $\cdot, \cdots$ & 11,109 & $\vee, \vee \wedge O$ & الثابت \\
\hline & & & & & $\cdot, \ldots$ & $9, Y \vee M$ & $\cdot, \cdot \vee \varepsilon$ & X4 \\
\hline
\end{tabular}


ومن النتائج السابقة يتضح ان الضرائب على السلع والخدمات بالوحده النقديه المحليه يؤثر على القيمه المضافه للصناعات التحويليه (بالاسعار الثابته للادولار الامريكى لعام

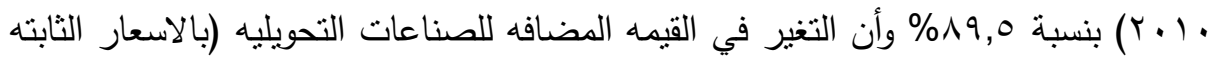

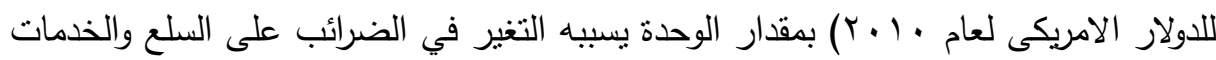

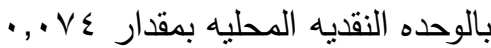
$Y 3=7.785+0.074 \times 4$

اختبار صحة الفرض الثاني: لاتوجد علاقه معنويه بين الحوافز الضريبيه وتنميه الطاقه

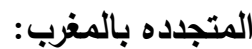

\section{هنغيراهت الصواسما}

\begin{tabular}{|c|c|c|}
\hline المتغير & الرهز & \\
\hline التابع & $\overline{\mathrm{Y} 4}$ & حصه الصناعه في أجمالى الأستهلاك النهائي للطاقه (\%) \\
\hline 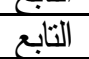 & Y5 & آنبعاثات CO2 / الناتج المحلى الآجمالى ( Kg co2 / / \$ 2010) \\
\hline التابع & Y6 & أجمالى الأنتاج من مصادر الطاقه المتجدده - مليون طن مكافئ نفط (Mtoe) \\
\hline التابع & $\overline{Y 7}$ & حصه مصادر الطاقه المتجدده في أجملى أنتاج الطاقه (\%) \\
\hline مستخل & $\mathrm{X} 1$ & إيرادات الضرائب \% من الناتج المحلى الأجمالى \\
\hline مستقل & $\mathrm{X} 2$ & إيرادات الضرائب بالوحده النققيه المحليه \\
\hline مسنتّل & $\mathrm{X} 3$ & الضرائب على السلع والخمات ( \% من القيمه المضافه للصناعه والخمات) \\
\hline مستقل & $\mathrm{X} 4$ & الضرائب على السلع والخمات بالوحده النقبيه المحليه \\
\hline
\end{tabular}

جدول(ه): يوضح معاملات الارتباط بين المتغيرات المستقلة والمتغير التابع

\begin{tabular}{|c|c|c|c|c|}
\hline X4 & $\mathbf{X 3}$ & $\mathbf{X} 2$ & X1 & \\
\hline${ }^{*} \cdot, \vee \vee \curlyvee q-$ & "**, , $\wedge \circ \wedge$ & "*, , & ***, $\wedge$ * & $\overline{\mathrm{Y4}}$ \\
\hline ***, & $* *, \wedge Y$. & ***, ,,.- & 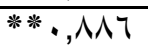 & $\overline{Y 5}$ \\
\hline **, , 970- & $*, 709$ & $* *, 9 \vee r-$ & $* *, \wedge) 1$ & Y6 \\
\hline **, , $\vee \backslash 1-$ & $* *, \wedge \Lambda 1$ & $*,, V Y V-$ & **.,9r & Y7 \\
\hline
\end{tabular}

يتضح من بيانات الجدول السابق:

• وجود علاقة ارتباط طردية دالة احصائيا بين حصه الصناعه في أجمالى الأستهلاك

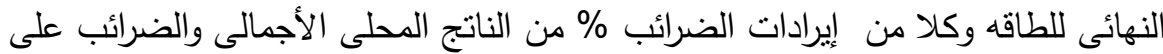


السلع والخدمات (نسبة من القيمه المضافه للصناعه)، حيث بلغت قيمة معامل الارتباط

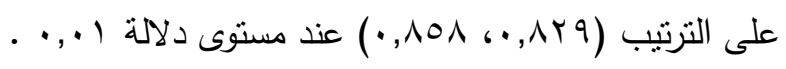

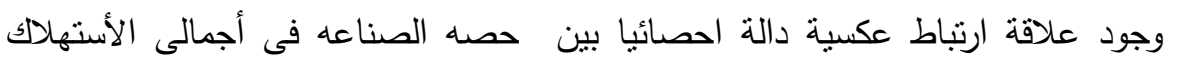

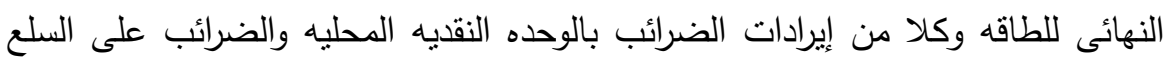

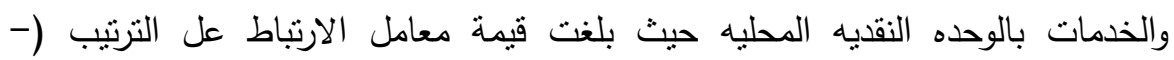

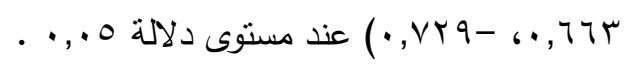

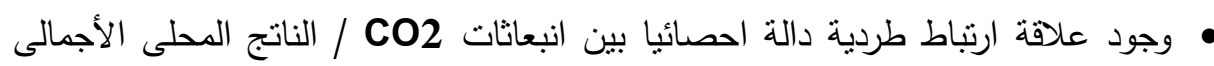
(US \$ 2010 / Kg co2)

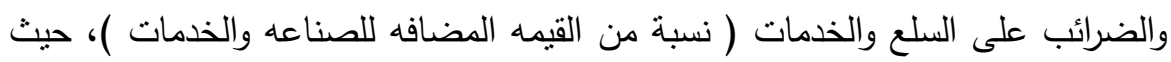

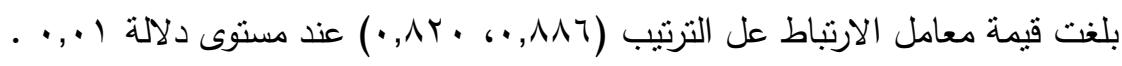

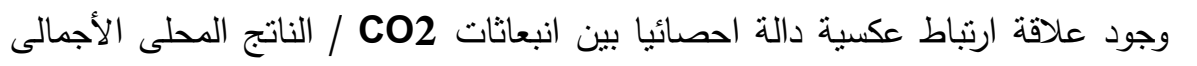
وكلا من إيرادات الضرائب بالوحده النقديه المحليه

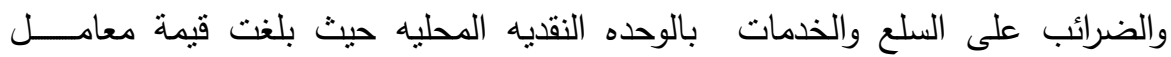

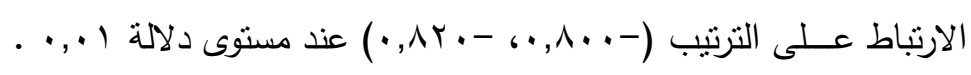

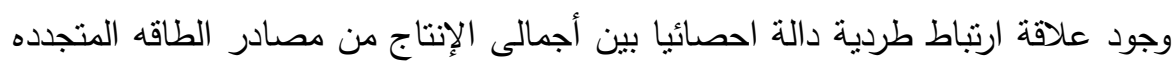

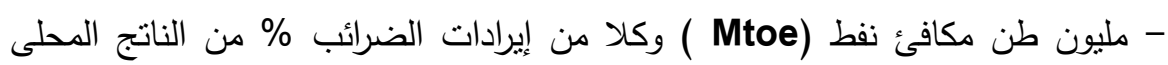

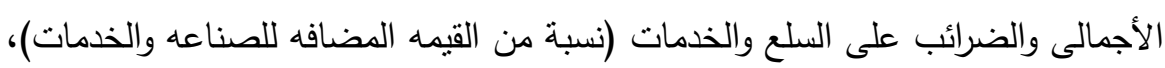

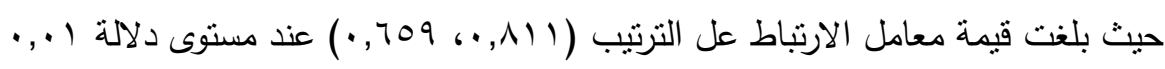
. , . ० ,

• وجود علاقة ارتباط عكسية دالة احصائيا بين أجمالى الأنتاج من مصادر الطاقه المتجدده - مليون طن مكافئ نفط (Mtoe) وكلا من إيرادات الضرائب بالوحده النقديه المحليه

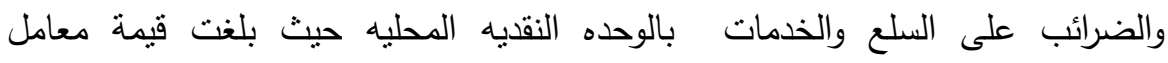

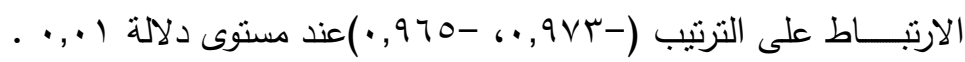


• وجود علاقة ارتباط طردية دالة احصائيا بين حصه مصادر الطاقه المتجدده فى أجمالى أنتاج الطاقه (\%) وكلا من إيرادات الضرائب \% من الناتج المحلى الأجمالى والضرائب

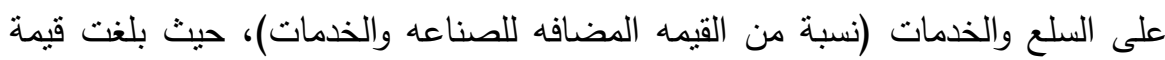

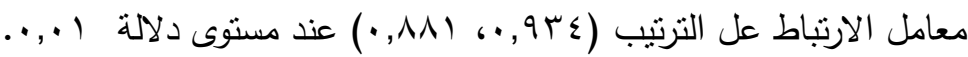

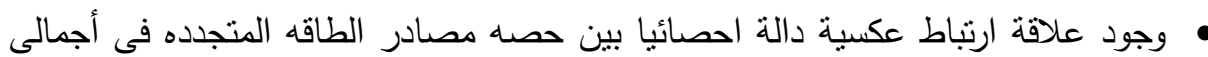
أنتاج الطاقه (\%) وكلا من إيرادات الضرائب بالوحده النقديه المحليه والضرائب على دائى

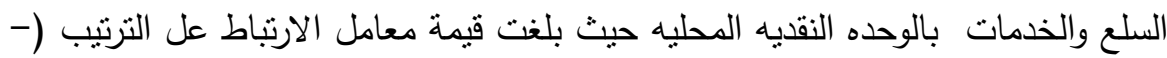

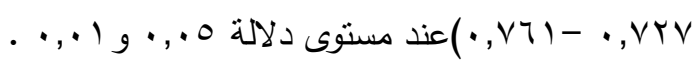

ومن خلال النتائج السابقة نم اجراء تحليل الانحدار المتعدد بطريقة الانحدار التدريجي لمعرفة اثز المتغيرات المستقلة وايهم اكثر تأثنير على المتغير التابع. أولاً: أثز المتغيرات المستقلة على المتغير التابع حصه الصناعه فى إجمالى الأستهلاك النهائى للطاقه (1\%)

\begin{tabular}{|c|c|c|c|c|c|c|c|c|}
\hline \multicolumn{9}{|c|}{ جدول( آ): يوضح نتائج تحليل الانحدار } \\
\hline 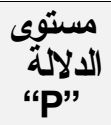 & "قيم" & التخديد & $\begin{array}{l}\text { التصليد } \\
\text { R2 } \\
\text { R2 }\end{array}$ & $\begin{array}{c}\text { الارتباط } \\
\text { R } \\
\text { مامل }\end{array}$ & $\begin{array}{l}\text { الالالة" مستوي } \\
\text { "P"P" }\end{array}$ & قيمة" "t" & المعلمة & المتغير \\
\hline & \multirow{2}{*}{$r 0,11$} & \multirow{2}{*}{$\cdot, V \cdot V$} & \multirow{2}{*}{ דו } & \multirow{2}{*}{$\cdot, 101$} & $\cdot, \ldots$ & 7,974 & $10, .99$ & الثابت \\
\hline & & & & & $\ldots$ & $0, .11$ & $\cdot, V Y T$ & X3 \\
\hline
\end{tabular}

يتضح من النتائج السابقة ان الضرائب على السلع والخدمات ( \% من من القيمه المضافه

للصناعه والخدمات) يؤثز على حصه الصناعه فى أجمالى الأستهلاك النهائى للطاقه (\%)

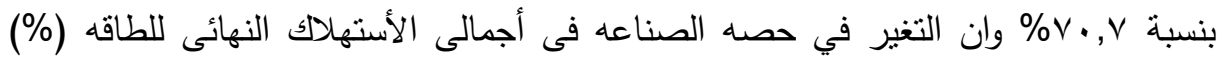
بمقدار الوحدة يسببه التغير في الضرائب على السلع والخدمات ( \% م من القيمه المضافه

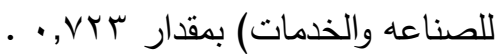
$\mathrm{Y} 4=15.099+0.723 \times 3$ 
ثنانياً: أثز المتغيرات المستقلة على المتغيرالتابع انبعاثات CO2 / الناتج المحلى الأجمالى :(US \$ 2010 / Kg co2)

\begin{tabular}{|c|c|c|c|c|c|c|c|c|}
\hline & & & & & \multicolumn{4}{|c|}{ جدول(V): يوضح نتائج تحليل الانحدار } \\
\hline 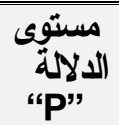 & "قَمة & المصليد & $\begin{array}{l}\text { التحلملد } \\
\text { R2 } \\
\text { R2 }\end{array}$ & $\begin{array}{c}\text { الارتباط } \\
\text { Re } \\
\text { Re }\end{array}$ & "الدلايةتوى & قيمة ت"t" & المطلمة & 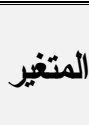 \\
\hline & \multirow{2}{*}{$r, \wedge r$} & \multirow{2}{*}{$\cdot, \mathrm{V} / \mathrm{I}$} & \multirow{2}{*}{$\cdot, \vee \wedge \wedge$} & \multirow{2}{*}{$\cdot, \wedge \wedge \mathrm{T}$} & (",AY. & דr, 11,9 & . & الثابات \\
\hline & & & & & $\bullet, \ldots$ & $0, V \mu$. & $\because, \cdots V$ & $\mathrm{X} 1$ \\
\hline
\end{tabular}

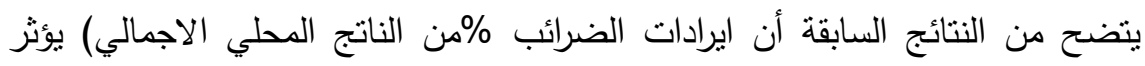

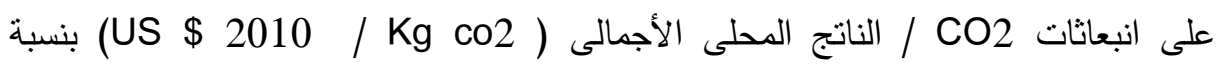

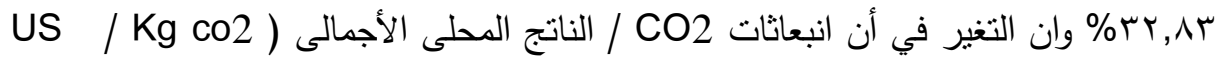
2010 \$) بمقدار الوحدة يسببه التغير في ايرادات الضرائب \% من الناتج المحلي الاجمالي) $\mathrm{Y} 5=0.339+0.007 \times 1$

ثالثاً: اثر المتغيرات المستقلة على المتغيرالتابع أجمالى الأنتاج من مصادر الطاقه المتجدده -

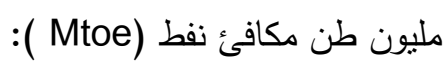

\begin{tabular}{|c|c|c|c|c|c|c|c|c|}
\hline مستوئ & قيمة "ق" & التخليد & $\begin{array}{l}\text { التحليد } \\
\text { R2 } \\
\text { R2 }\end{array}$ & الارتباط & $\begin{array}{l}\text { "الدلةتئي } \\
\text { "P" } \\
\text { "P" }\end{array}$ & قيمة ت & المعلمة & المتغير \\
\hline \multirow[b]{2}{*}{$\cdot, \cdots$} & \multirow[b]{2}{*}{171,90} & \multirow[b]{2}{*}{$\cdot, 9 \leqslant Y$} & \multirow[b]{2}{*}{$\cdot, 9 \leq V$} & \multirow[b]{2}{*}{. $9 \vee r$} & $\overline{e, \ldots}$ & $T 1, T \cdot V$ & $r, 177$ & الثابابت \\
\hline & & & & & & IY,VYT & $\begin{array}{c}- \\
., \cdots \wedge\end{array}$ & $\times 2$ \\
\hline
\end{tabular}

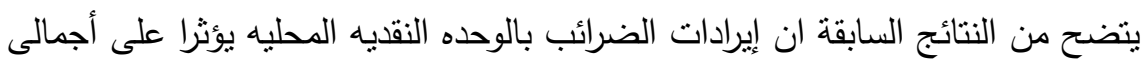

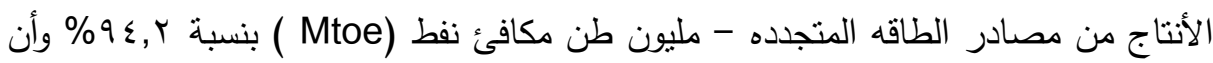
التغير في أجمالى الأنتاج من مصادر الطاقه المتجدده - مليون طن مكافئ نفط (Mtoe) بمقدار الوحدة يسببه التغير في إيرادات الضرائب بالوحده النقديه المحليه بمقدار - > ..,... Y6 = 3.166-0.008 X2 
رابعاً: انز المتغيرات المستقلة على المتغيرالتابع حصه مصادر الطاقه المتجدده فى أجمالى

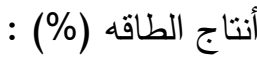

\begin{tabular}{|c|c|c|c|c|c|c|c|c|}
\hline & & & & & \multicolumn{4}{|c|}{ جدول(9): يوضح نتائج تحليل الاتحدار } \\
\hline "الالالةي & قيمة "ق" & التخديد & $\begin{array}{l}\text { التحليد } \\
\text { R2 }\end{array}$ & $\begin{array}{c}\text { الارتباط } \\
\text { معامل } \\
\text { الم }\end{array}$ & "الدلالةتي & قيمة" & المطلمة & المتغير \\
\hline \multirow{2}{*}{$\cdot, \cdots$} & \multirow{2}{*}{ Tा, } & \multirow{2}{*}{$\cdot, \wedge \circ \wedge$} & \multirow{2}{*}{$\cdot, \lambda V Y$} & \multirow{2}{*}{ } & $\cdot, \ldots$ & $\varepsilon V, 1 \cdot \varepsilon$ & $\Delta \Gamma, I Y)$ & الثابت \\
\hline & & & & & $\cdot, \ldots$ & $\mathrm{V}, \wedge \mathrm{\Lambda}$ & $\cdot, T \cdot T$ & $\mathrm{X} 1$ \\
\hline
\end{tabular}

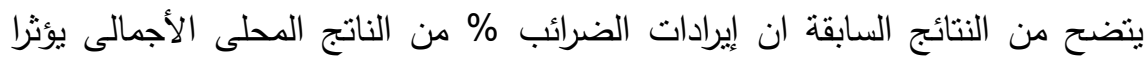

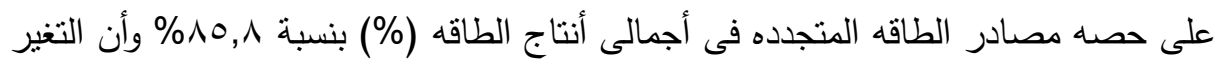
فيه بمقدار الوحدة يسببه التغير في إيرادات الضرائب \% من الناتج المحلى الأجمالى بمقدار $\cdot, T \cdot 4$

$\mathrm{Y} 7=83.121+0.603 \times 1$

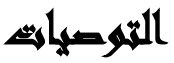

• وضع نظام ضريبي بيئي عادل ومحفز للإستثمار في تكنولوجيات الإنتاج النظيف ومشاريع الحد من نلوث البيئة واقتصاد الطاقة. • نظرا لمحدوديه الحوافز الضريبية الممنوحة للاستثمار فى المجال البيئي يمكن استدراكها

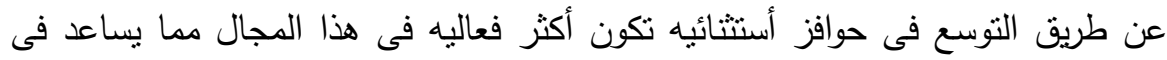
نجاح الأنشطه والمشاريع المرنبطه بالحد من التلوث وحمايه البيئة مثل: اعتماد الأهلاكى

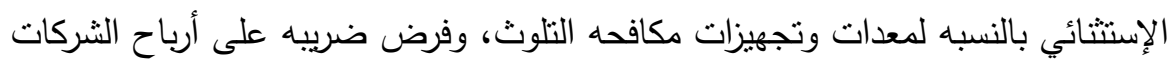
بمعدل منخفض بالنسبه للمؤسسات التى تقدم خدمات بيئيه او التى تقوم باستثمار جزء من بن أرباحها فى المجال البيئي. •لابد من دراسة الحوافز الضريبية لاسيما الاعفاءات منها قبل منحها ويفضل منح الاعفاءات وبقية الحوافز حسب نوع الصناعة والنشاط الاقتصادي ونوع الطاقه المستخدمه

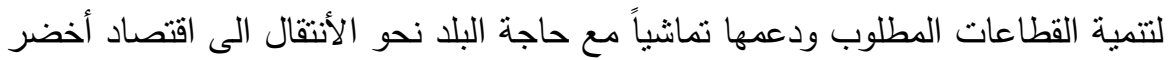


وتتمنل هذه الأعفاءات فى: الأعفاء من ضريبه القيمه المضافه وكذلك الأعفاء من الرسوم

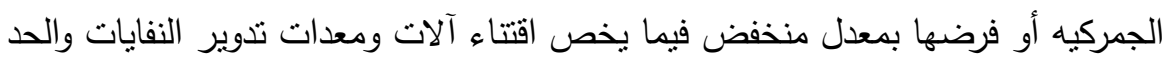

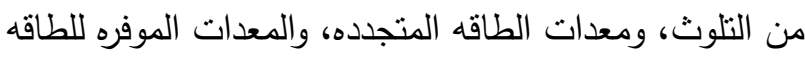
• وضع نموذجا قتصادي جديد يحافظ على الرأسمال الطبيعي ويضمن أعلى مستوى من

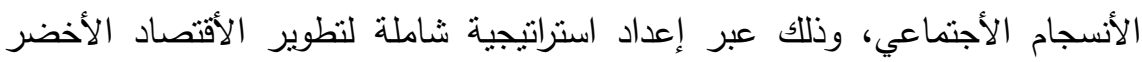

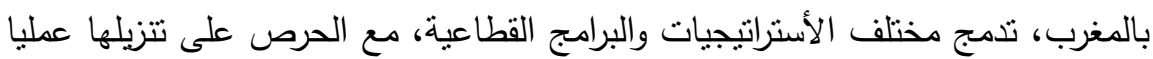

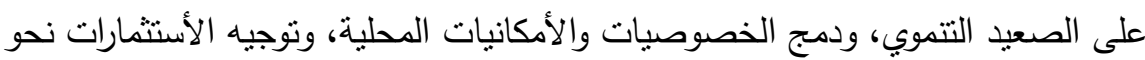

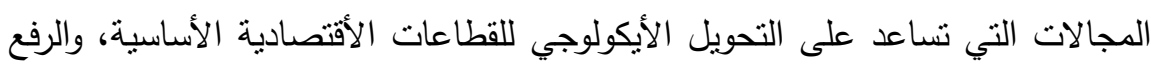

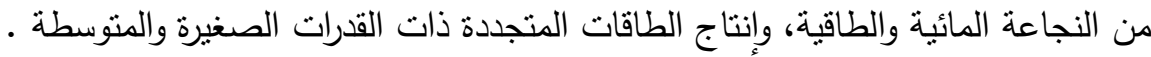

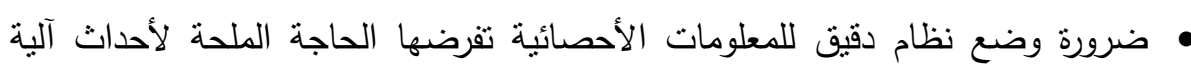
معلوماتية لتجميع ومعالجة المعطيات التي تغطي مختلف وحدات التتظيم الأداري للدوله، والتى تتكل آلية ضرورية في اتخاذ القرار ، وبروز فعال في مجال التتمية، ضمن دمن ديناميكية اقتصاد المعرفة من خلال الأعتماد على التكنولوجيات الجديدة للأعلام والاتصال.

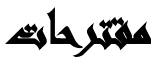

دراسة أثز فرض ضريبه الكربون في توجيه السلوك البيئيللمؤسسات الاقتصادية فى ج •م.عتحليل دور الضرائب البيئيه فى تتميه قطاع الصناعات التحويليه بجمهوريه مصر العربيه.

\section{المرالئ}

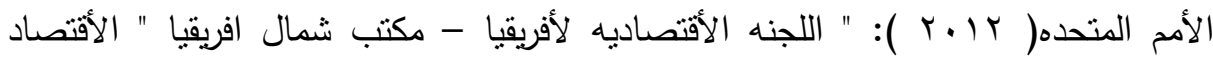

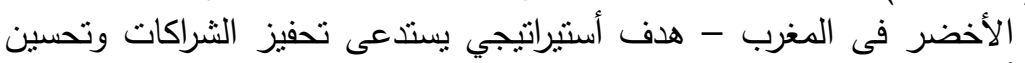

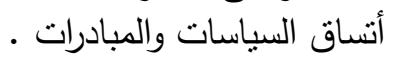

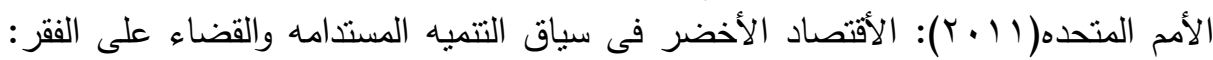

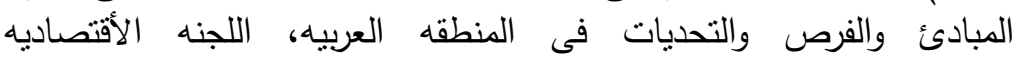

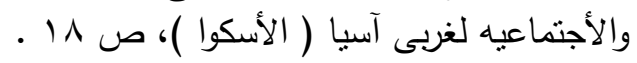

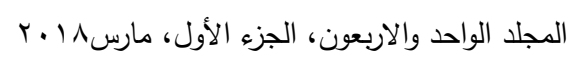




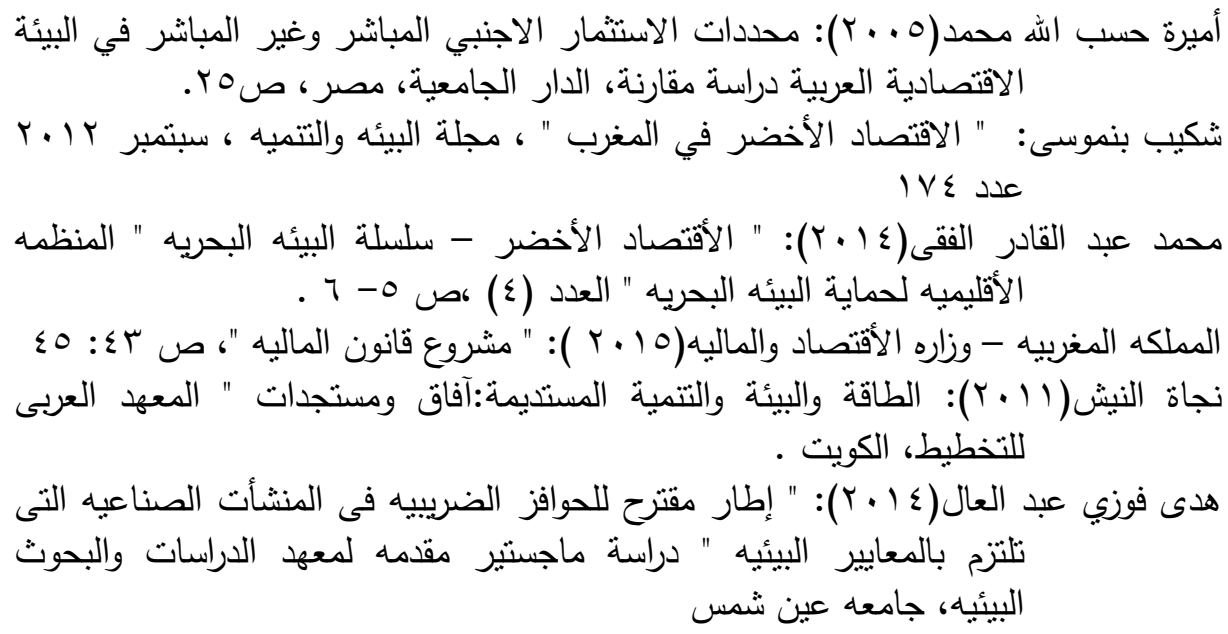

IEA statistics (2011): CO2 emissions from fuel combustion. International Energy Agency (IEA)

Supersberger N, Fuhrer L.(2011): Integration of renewable energies and nuclear power into North African energy systems: an analysis of energy import and export effects، Energy Policy,39:4458-65

Ministry of Energy, Mines, Water and Environment (MEMEE) (2011): La Strategie Energetique Nationale Bilan d' etape.

Schilling J, Freier KP, Hertige E, Scheffrana J. (2012): Climate change, vulnerabilityandadaptation in North Africa with focus on Morocco, agriculture. Ecosyst Environ ;156:12-26.

T.kousksou et al. (2015): ,"Morocco 's Strategy for energy security and low Carbon growth ", University of British ColumbiaCanada.

Erin Elizabeth Troland (2015):, " Essays On Public Spending and Taxation in Developing Countries " ,UNIVERSITY OF CALIFORNIA, SAN DIEGO .

Ciolkosz Daniel (2016 ): Penn State College Of Agricultural Sciences. 
أحمد فؤاد مندور وآخرون

\title{
THE ROLE OF TAX INCENTIVES IN THE DEVELOPMENT OF THE GREEN ECONOMY IN MOROCCO - ANALYTICAL STUDY
}

Mandour, A. F. ${ }^{(1)}$; El Said, Iman ${ }^{(2)}$ and Shahin, Samar, S. M. ${ }^{(3)}$ 1) Faculty of Commerce, Ain Shams University 2) Faculty of Commerce, Ain Shams University 3) Tax Authority of Egypt

\begin{abstract}
With the increasing pressures on the environment as a result of the various commitments and activities that serve the economy, especially in the major industrial countries ... The concept of the green economy is beginning to emerge, and if we look at Morocco as a model for its poor and developing countries, it faces a large number of huge challenges. Poverty reduction, additional job creation, resource efficiency and energy security, low-carbon strategies for industrial development.

The study aimed to highlight the role of taxes (because of its incentives both positive and negative) in the development of the green manufacturing and renewable energy sector in Morocco. The researcher used the analytical descriptive method and the appropriate statistical tests to test the validity of hypotheses and to answer the study questions

\section{The results are as follows:}

- Taxes on goods and services in the local monetary unit and taxes on goods and services (\% of value added for industry and services) affect the emissions of $\mathrm{CO} 2$ from the manufacturing and construction industries (\% of total fuel combustion) by $79.4 \%$.

- Taxes on goods and services (\% of value added for industry and services) affect the share of industry in total final consumption of energy (\%) by $70.7 \%$.
\end{abstract}

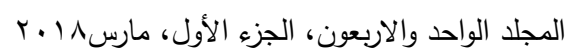


- Tax revenues in the local monetary unit affect the total production of renewable energy sources - million tons of oil equivalent (Mtoe) by $94.2 \%$.

In light of this, the study concluded several recommendations, the most important of which are: the inclusion of environmental and social costs within the price of the product or service by tax, fee or fine or through cheaper negotiable schemes.

Key words: Morocco's green economy - Renewable energy in Morocco

- Tax incentives in Morocco 